\title{
EL PAIMEF: UN PROGRAMA DE ATENCIÓN A MUJERES VÍCTIMAS DE VIOLENCIA EN EL ESTADO DE CHIAPAS
}

\author{
PAIMEF: A CARE PROGRAM FOR WOMEN VICTIMS \\ OF VIOLENCE IN CHIAPAS STATE \\ Inés Castro Apreza \\ Centro de Estudios Superiores de México y Centroamérica \\ Universidad de Ciencias y Artes de Chiapas \\ castroapreza@yahoo.com.mx
}

\section{RESUMEN}

Este artículo analiza las fortalezas y debilidades del Programa de Apoyo a las Instancias de Mujeres de las Entidades Federativas (PAIMEF) en Chiapas. Se centra en algunos de los problemas que afronta dicho programa en la atención a mujeres víctimas de violencia, los cuales afectan negativamente la calidad del servicio que presta: la débil vinculación institucional entre el PAIMEF y las autoridades, o el papel de los Juzgados de Paz y Conciliación y el desconocimiento de las lenguas originarias por parte de las profesionales que colaboran en las unidades ubicadas en los municipios indígenas. Pese a ello, a través de la percepción de las usuarias, se valoran las ganancias simbólicas como el acompañamiento que tienen de dichas profesionales, así como la solución a algunas de sus demandas.

PALABRAS CLAVE: PAIMEF, atención a la violencia, violencia de género, violencia contra mujeres indígenas.

\section{ABSTRACT}

This article analyzes the strengths and weaknesses of the Program to Support Women's Organizations in the States (Programa de Apoyo a las Instancias de Mujeres de las Entidades Federativas/PAIMEF), in Chiapas. It focuses on some of the issues faced by this care program for women victims of violence, which negatively affect the quality of its services, i.e., the weak institutional bond between PAIMEF and the authorities, or the role played by the Peace and Conciliation Courts and the fact that the professionals collaborating in the units located in indigenous municipalities lack knowledge of native languages. Despite this, users perceive and value symbolic gains such as the accompaniment of professionals, as well as the achievement of solutions to some of their demands.

KEY WORDS: PAIMEF, attention to violence, gender violence, violence against indigenous women. 


\section{INTRODUCCIÓN}

E ntre los estudios de mujeres y género en Chiapas, ${ }^{1}$ pocos se refieren sistemáticamente a la violencia que viven las indígenas y las mestizas² (cfr. Jiménez 2011, González y Valdez 2008, Olivera 2008 y 1979, López 2006, Soriano 2005, Freyermuth 2004a y 2004b, Castro 2004, Hernández 2004, 2002 y 1998). Sorprende la constatación anterior en una entidad usualmente asociada con una larga tradición organizativa que confronta y cuestiona al Estado, donde las mujeres han sido partícipes directas. Pero su invisibilización y su estereotipación (Garza y Toledo 2004, Toledo y Garza 2003) pueden ayudarnos a entender que la defensa de las comunidades y organizaciones protagonizada por ellas, con altos costos, no haya sido enfocada en términos de violencia hacia las mujeres, la cual apenas recientemente empezó a ser asumida como un problema.

Hemos aprendido a pensar de una nueva forma la violencia en virtud del trabajo feminista en la entidad y de la Ley General de Acceso de las Mujeres a una Vida Libre de Violencia (Cámara de Diputados 2007), ${ }^{3}$ así como de los instrumentos internacionales disponibles, en particular, la Convención sobre la Eliminación de Todas las Formas de Discriminación contra la Mujer (CEDAW 1979) y la Convención Interamericana para Prevenir, Sancionar y Erradicar la Violencia contra la Mujer «Convención Belem do Pará» (1994). Esa nueva manera de comprender el fenómeno se refleja en el discurso y los programas puestos en operación por mujeres y hombres de organismos no gubernamentales, así como de las instituciones estatales. Sin embargo, todavía no es notoria en estudios sistemáticos sobre la violencia contra las mujeres ni sobre políticas públicas orientadas a mujeres, con excepciones notables que abordan la violencia de género (Sedesol et al. 2011, Ulloa et al. 2009), la muerte materna (Freyermuth 2004b, Freyermuth, Manca 2000) y la salud (Tuñón 1997). A este último respecto se puede señalar que un marcado distanciamiento de la academia y los feminismos respecto de las políticas de Estado se ha traducido no pocas veces en posturas antigubernamentales: una lar-

\footnotetext{
1 Como referencia principal tomo la Colección Chiapas del Instituto de Estudios Indígenas de la Universidad Autónoma de Chiapas, una fuente básica para los estudios de mujeres y género en el estado. Dejo fuera las tesis de licenciatura y posgrado que se han realizado al respecto en diferentes instituciones, que sin duda aportan sustancialmente al tema. Actualmente, la sección «Género» de dicha colección cuenta con alrededor de 400 títulos.

2 Mantendré el término mestiza para referirme a mujeres no indígenas, ya que se trata de un uso cotidiano generalizado y muy presente en la constitución de las identidades.

${ }^{3}$ En adelante, Ley General.
} 
ga tradición antiestatalista caracteriza a diversos movimientos y organizaciones sociales en la entidad.

Este artículo sobre el Programa de Apoyo a las Instancias de Mujeres de las Entidades Federativas (PAIMEF) intenta ser un referente de estudio basado en modelos de atención a mujeres víctimas de violencia diseñados desde la perspectiva de formulación de políticas públicas, así como desde los estudios de género, los estudios feministas y aquellos referidos a la violencia contra las mujeres. El PAIMEF, un área de operación del Instituto de Desarrollo Social (Indesol) puesto en operación en Chiapas desde 2007, tiene como objetivo «contribuir a prevenir y atender la violencia contra las mujeres a través de las acciones que realizan las Instancias de Mujeres en las Entidades Federativas, en coordinación con las diversas instituciones gubernamentales y sociales involucradas en esta materia» (Gobierno de México 2015). Bajo esta consideración analizo la atención de mujeres en situación de violencia (poco se trabajaba la prevención en la época en que se hizo esta investigación), para lo cual me enfoco en los problemas centrales que el programa afronta y que inciden negativamente en la calidad de la atención. Dichos problemas son las condiciones materiales inadecuadas, una débil vinculación institucional entre el PAIMEF y las autoridades, el papel de los Juzgados de Paz y Conciliación y el desconocimiento de los idiomas originarios por parte de las profesionales que ejercen en las unidades ubicadas en los municipios indígenas. Sin embargo, también me ocupo de la buena percepción de las usuarias del servicio recibido; en tal sentido, señalo que estas mujeres valoran, por encima de todo, el acompañamiento que tienen de las profesionales, así como la solución de algunas de sus demandas.

\section{METODOLOGÍA}

Este trabajo se basa en la investigación que realicé para la Secretaría de Desarrollo y Empoderamiento de la Mujer (SEDEM) y el PAIMEF de Chiapas entre agosto y diciembre del año 2012, bajo el siguiente rótulo: Programa de Acompañamiento y Mejora de la SEDEM, de las Acciones del Proyecto PAIMEF 2012 y los Servicios de Atención para Mujeres en Situación de Violencia, en su caso, sus Hijos e Hijas (Castro 2012a. En adelante, Programa de Acompañamiento). El objetivo específico de dicho programa fue el diseño de protocolos regionalizados de atención en la entidad —tomando como base el Modelo de Atención de SEDEM-Chiapas 
2012) - donde existían 22 unidades atendidas por una abogada y una psicóloga (o trabajadora social) en diferentes regiones. Este análisis se basa en los dos productos entregados -Programa de Acompañamiento (Castro 2012a) y Protocolos por Regiones (Castro 2012b) - , pero retoma centralmente las entrevistas a profundidad realizadas a usuarias y profesionales.

Durante la investigación revisé documentos (Sedesol et al. 2010) y bases de datos estadísticos elaborados previamente en el propio PAIMEF para contar con un panorama del estado y desarrollo del programa. Asimismo, entrevisté a las coordinadoras del PAIMEF, ${ }^{4}$ si bien la comunicación con estas últimas fue continua porque el trabajo de investigación suponía recomendaciones sobre la marcha para la mejora del programa. Sin duda, el hecho de que el PAIMEF haya sido diseñado desde la federación, desde donde fluyen las directrices hacia los estados para su ejecución, es determinante en su buen funcionamiento. De aquí la relevancia de los modelos de atención. Por lo demás, se hizo evidente la importancia de que la coordinación del programa — para su buen desarrollo_ estuviera en manos de mujeres con experiencia de trabajo con perspectiva de género en organismos no gubernamentales.

Por otro lado, consulté modelos de atención a mujeres que viven violencia, realizados tanto nacionales como de otros países. En México: Modelo de Atención Integral a las Mujeres Víctimas de Violencia de Género (SEDEM-Chiapas 2012), Modelo ecológico para una vida libre de violencia de género en ciudades seguras (Incháustegui y Olivares 2011), Modelo de Atención a Mujeres en Situación de Violencia. Apegado a la Ley de Acceso a una Vida Libre de Violencia para las Mujeres en el Estado de Chiapas, (Sedesol et al. 2011), Modelo Integrado para la Prevención y Atención de la Violencia Familiar y Sexual (Secretaría de Salud 2009). Revisé asimismo modelos de Chile (Arensburg y Pujal 2014), Colombia (Moreno et al. 2013, Bello-Urrego 2013, Romero et al. 2009), Cuba (López 2009) y Perú (Garmendia et al. 2010), este último caso referido específicamente a víctimas de violencia política. La búsqueda de información sobre violencia de género o violencia basada en el género, así como violencia hacia las mujeres -los conceptos clave que consideré- atendió principalmente análisis centrados en la atención a mujeres víctimas de violencia, en los que se hace referencia sobre todo al accionar de los profesionales de la salud. Dicho material ha sido el marco

4 Entrevistas a Rocío García, coordinadora general del PAIMEF en Chiapas 2010-2012, agosto 2012; y Marissa Revilla, subcoordinadora de Seguimiento a las Unidades del PAIMEF en Chiapas 2010-2012, diciembre 2012. 


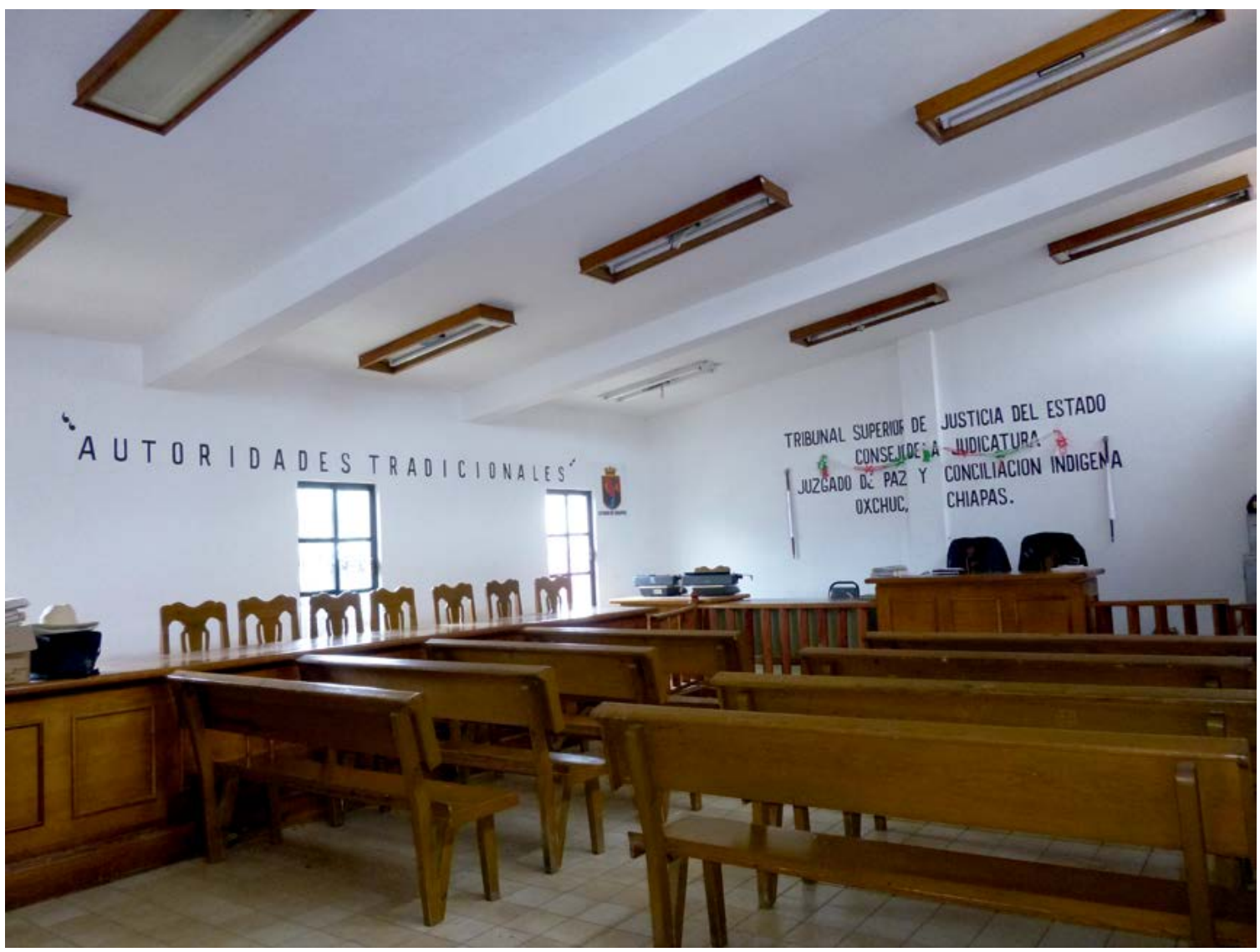

de interpretación teórico-política del fenómeno de la atención a mujeres que viven violencia de género.

Si bien los casos revisados no son iguales al PAIMEF, afrontan problemas similares, lo que muestra, por un lado, que la violencia contra la mujer ha sido ya reconocida al más alto nivel como un problema de salud pública y un obstáculo al desarrollo de las naciones, y por otro, que aún no encontramos la estrategia precisa para erradicarla.

Las entrevistas semiestructuradas a profundidad y el trabajo etnográfico en 18 de las 21 unidades fueron mis herramientas de investigación básicas. La técnica de la entrevista fue aplicada a usuarias (un total de 36), es decir, mujeres que acuden a las oficinas del programa —o unidades, como también las llaman- para recibir dicho servicio, así como a profesionales que lo prestan (31 en total: 15 psicólogas, 15 abogadas y una trabajadora social). Entre las usuarias entrevisté a seis centroamericanas residentes en Huixtán, Tapachula, Tuzantán, Pichucalco y Ciudad Hidalgo, y a 12 mujeres indígenas originarias y residentes en Altamirano, Jitotol, Huixtán, Las Margaritas, Oxchuc, Tecpatán y Tenejapa. 
Las usuarias entrevistadas fueron «nuevas», es decir, aquellas recién llegadas para recibir la atención, y «de seguimiento», esto es, quienes tenían ya algunos meses e incluso años de trabajar con las profesionales. La manera de hacer la cita respectiva con las usuarias fue, necesariamente, por medio de las mismas profesionales, ya que son estas quienes tienen el contacto directo y continuo. Esto en principio podría sesgar la valoración de las usuarias respecto del servicio recibido por parte de las profesionales, en la medida en que la elección realizada pudo darse en función de con quiénes se tuvieran mejores resultados. Sin embargo, el trabajo etnográfico permitió ponderar las entrevistas todas, tanto de las usuarias como de las profesionales, ya que incluyó el conocimiento del terreno específico en que tiene lugar el servicio: las propias oficinas, la vinculación con las autoridades municipales y las instancias de procuración y administración de justicia. Además, ayudó mucho que las usuarias fueran «de seguimiento» porque esto permitía ver todo el trabajo realizado en el tiempo, y «nuevas» porque el primer contacto con el PAIMEF es fundamental para saber las primeras opiniones que les merece el programa y si ellas darán continuidad al servicio.

El guión de la entrevista contempló el perfil de la entrevistada (nombre, edad, estado civil, número de hijos e hijas, escolaridad), el problema por el cual acudió al PAIMEF, cómo se enteró del programa, cuándo lo hizo y la atención recibida a lo largo de su experiencia concreta (una temporalidad muy variable entre las usuarias). Los resultados en términos de demandas interpuestas y ganadas (o no ganadas), pero también las ganancias simbólicas, entre estas el acompañamiento referido, se consideraron significativas en la valoración del programa por parte de las usuarias.

Sostuve diversos encuentros-entrevistas con autoridades de algunos ayuntamientos (en Ciudad Hidalgo, Huixtán, San Cristóbal, Tapachula, Tuzantán y Oxchuc), centrados en las políticas municipales orientadas a apoyar a mujeres, familias, adultos mayores, etc., y la relación establecida con el PAIMEF. El objetivo de estos encuentros fue verificar la existencia o no, así como el grado de vinculación y coordinación institucional respecto de la atención a mujeres víctimas de violencia. Las diferentes maneras de concebir la violencia hacia las mujeres se reveló como un factor importante en las estrategias adoptadas por cada institución. Y pude, finalmente, presenciar los talleres de constelaciones familiares impartidos a las profesionales del PAIMEF, como parte del apoyo terapéutico que ellas mismas requieren por su tipo de labor, así como una sesión de un grupo de autoayuda promovido en una de las unidades y abierto de forma voluntaria a las 
usuarias. Estas acciones, junto a los talleres de género que reciben las profesionales, son parte de las acciones que llamo «con perspectiva de género», promovidas fuertemente por las coordinadoras y que favorecían el servicio.

\section{LA ATENCIÓN A MUJERES EN SITUACIÓN DE VIOLENCIA: UN PANORAMA GENERAL}

Existen diversas maneras de definir la violencia contra las mujeres (Bello-Urrego 2013, Osborne 2008, Arce-Rodríguez 2006, Álvarez 2006), ${ }^{5}$ condicionadas todas ellas por contextos particulares y concepciones culturales determinadas, y que, sin duda alguna, no solo ofrecen definiciones sino también, al hacerlo, suponen vías de intervención precisas y abordajes con alcances y limitaciones. Como afirma Bello-Urrego (2013:117), «los marcos de interpretación en ningún caso son neutrales, [sino que] implican una elección política, con independencia de la intención consciente de quien los usa».

El concepto de violencia de género o violencia basada en género es, hasta el momento, el de mayor consenso porque incluye precisamente esa categoría relacional que es el género (mujeres-hombres), y que se puede y debe usar como una fuente primaria de relaciones significantes de poder (Scott 2000). Como señalan Gimeno y Barrientos (2009:37), al hablar de violencia de género, desde el feminismo, se busca «subrayar la centralidad que tiene el género como principio organizador y normativizador de los sistemas sociales, en este caso de la familia heterosexual donde se ponen en juego construcciones como maternidad/paternidad, feminidad/masculinidad, división sexual del trabajo, etc.»

Sin embargo, la categoría de violencia de género no ha dejado de recibir críticas. El uso de la categoría de "género» puede subsumir la específica violencia contra las mujeres y asumir el riesgo de verse diluida la responsabilidad de los agresores hombres (Rivera-Garretas 2001:37-38). Gimeno y Barrientos (2009) discuten, en el marco de un arduo debate que tuvo lugar en España, por qué en la violencia de género no debe incluirse la violencia producida entre parejas homosexuales y por qué hacerlo no es un argumento feminista y sí, en cambio, debilita

${ }^{5}$ Entre algunas denominaciones se encuentran: mujer maltratada, mujer golpeada, malos tratos en la pareja, violencia contra las esposas, violencia doméstica, violencia contra la mujer, violencia íntima, violencia doméstica hacia la mujer por su pareja, violencia en la pareja, la pareja en situación de violencia, la pareja violenta (citado en Álvarez 2006), violencia de género y violencia machista (Gimeno y Barrientos 2009). Todas ellas dan cuenta del intento de las feministas por encontrar la categoría adecuada. 
la lucha contra la violencia machista. Por su parte, Femenías y Soza (2009:56), en su análisis del poder y la violencia sobre el cuerpo de las mujeres, observan que considerar la violencia de género solo «como el subproducto de una relación enferma entre un varón y una mujer y aislarla del marco constitutivo y reproductor de la desigualdad entre ambos conlleva el peligro de quitar la parte política a lo personal». Seguramente por todo ello es relevante que la Ley General (Cámara de Diputados 2007) en México, en su artículo V, se refiera específicamente a «violencia contra las mujeres», definida como «cualquier acción u omisión, basada en su género, que les cause daño o sufrimiento psicológico, físico, patrimonial, económico, sexual o la muerte tanto en el ámbito privado como en el público».

Más allá de los problemas que podemos afrontar con este concepto, Raquel Osborne (2008) plantea que uno de los grandes logros del feminismo contemporáneo es que «cambió nuestra comprensión de la sexualidad y de las relaciones entre mujeres y varones al identificar la violencia sexual como un elemento importante en el mantenimiento de la subordinación de las mujeres». Sin atribuírselo siempre a una conquista de las luchas feministas, la mayoría de los estudios reconocen que la violencia contra las mujeres ya es considerada como una violación a los derechos humanos y un obstáculo para la paz y el desarrollo de los países.

En Chiapas, como en el contexto cubano (López 2009) o venezolano (García et al 2003:67-68), y muchos otros, la atención de mujeres en situación de violencia fue una labor iniciada por organizaciones no gubernamentales que, en el contexto local, nacieron en los años noventa del siglo XX. En particular, la formación del Grupo de Mujeres de San Cristóbal (Colem) fue una iniciativa de mujeres coletas, tuxtlecas y de otros estados del país para protestar y organizarse a raíz de una violación tumultuaria a una mestiza, así como de violaciones a niñas indígenas por caciques de San Juan Chamula (Castro 2016, Salazar 2013). Si bien este escenario de 1989-1991 fue el contexto en el que se empezó a reflexionar sobre el cuerpo y la violencia sexual, así como trabajar con mujeres víctimas de abuso, en particular, insisto, el propio Colem (véase Hernández 2004), pasarían varios años antes de que el Estado tomara en sus manos esta labor.

Como sugiere Raquel Osborne (2008:89-101), no obstante todos los logros del feminismo contemporáneo en España fue necesario el reconocimiento al más alto nivel para que los Estados tomaran cartas en el asunto, lo que ocurrió luego de la Declaración de Naciones Unidas sobre la Eliminación de la Violencia contra la Mujer en 1993. Ciertamente, en México la política institucional de género ha sido fuertemente impulsada desde el año 2000 (Rodríguez, 2009). Entre los 
indicadores más destacables al respecto en Chiapas está la creación del Instituto Estatal de la Mujer (IEM) en 2001, actualmente SEDEM; la promulgación de la Ley de Acceso a una Vida Libre de Violencia para las Mujeres en el Estado de Chiapas (Poder Judicial del Estado de Chiapas 2007. En adelante, Ley de Acceso) y de la Ley para la Igualdad entre Mujeres y Hombres para el Estado de Chiapas (Poder Judicial del Estado de Chiapas 2009); la creación del Centro de Justicia para las Mujeres (Cejum) en 2011, así como la ejecución de acciones y programas específicos. Sin estar todavía armonizadas aquellas leyes con los códigos locales, lo que supone en sí mismo importantes limitaciones en la defensa de las víctimas de violencia, sí han permitido ser una base para identificar diferentes tipos de violencia, instaurar programas como el PAIMEF e impulsar otras plataformas feministas.

Con las definiciones aportadas por la Ley General es posible reconocer diferentes tipos de violencia más allá de la física, que es la más fácilmente vista como tal. En el PAIMEF el modelo de atención está basado en esta ley, lo que, a juzgar por las entrevistas, permite que las mujeres en situación de violencia identifiquen de qué maneras la viven. Al identificar que diversas prácticas constituyen tipos o modalidades de violencia, comienzan un proceso de desnaturalización de la violencia.

Además, haber incluido en dicha ley la violencia feminicida ha redundado favorablemente en la lucha contra esta: es «la forma extrema de violencia de género contra las mujeres, producto de la violación de sus derechos humanos, en los ámbitos público y privado, conformada por el conjunto de conductas misóginas que pueden conllevar impunidad social y del Estado y puede culminar en homicidio y otras formas de muerte violenta de mujeres» (Ley General, Capítulo V, artículo 21). Si las luchas de las mujeres fueron por delante de leyes y acciones del Estado, como señalé arriba, estas importantes definiciones conceptuales han redundado en el reconocimiento preciso de los feminicidios y en la lucha contra estos, lo que ha dado como resultado, por un lado, la cuantificación del problema y el seguimiento jurídico de algunos casos y, por otro, el ordenamiento de una información más sistemática con fines de divulgación y toma de conciencia en la población. ${ }^{6}$ Osborne (2008) señala con razón: «llevar una contabilidad eleva el fenómeno de anécdota a categoría, conduciendo a su mayor visibilidad».

En Chiapas, un elemento favorable para todo lo anterior ha sido el trabajo de incidencia política de mujeres que ubico en la vertiente del feminismo institu-

- Comunicación personal de la abogada feminista Martha Figueroa Mier, fundadora del Grupo de Mujeres de San Cristóbal Colem, A. C. 
cional, es decir, aquellas que buscan incidir en las políticas públicas e instancias gubernamentales, ${ }^{7}$ cuyo número posiblemente haya crecido en los últimos años. Seguramente lo anterior no significa que se haya diluido la frontera entre Estado y sociedad civil en la entidad, que parecía infranqueable en los años ochenta del siglo XX, pero sí ha ayudado a todas las ganancias señaladas respecto de la visibilización de la violencia contra las mujeres y las acciones de atención y prevención establecidas.

En virtud de este trabajo de las feministas y de las organizaciones no gubernamentales, en la década de los noventa "se consolida» la intervención de las instituciones gubernamentales en la atención a la violencia de género contra las mujeres (Modelo de Atención Integral del SEDEM-Chiapas 2012:69). En este momento, basarse en los instrumentos internacionales, en particular la CEDAW y la Convención Belem do Pará, ya era la tónica común.

En el periodo 2011-2012, los Institutos Estatales de las Mujeres en la república mexicana se dieron a la tarea de elaborar modelos locales de atención a mujeres en situación de violencia, para lo cual se retomaron los ya existentes a nivel general. En efecto, para ese momento se contaba con modelos de política pública para atender a mujeres víctimas de violencia de género — como se la ha preferido llamar en México_, y, si bien hay diferencias entre ellos, algunos son relevantes para el caso de Chiapas. El denominador común es que intentan ofrecer una atención «integral», «ecológica» u «holística» a las mujeres en situación de violencia.

El primero de ellos, el Modelo de Atención Integral a las Mujeres Víctimas de Violencia de Género (SEDEM-Chiapas 2012:74), señala como objetivo general «proporcionar herramientas conceptuales y metodológicas que garanticen la homologación de los procedimientos de actuación de las y los profesionales que atienden los casos de violencia de género contra las mujeres en un marco de derechos humanos, ciudadanía de las mujeres y perspectiva de género con el fin de que las mujeres víctimas de violencia reciban la atención integral que nece-

\footnotetext{
7 La identificación de un feminismo institucional con esta característica está inspirada inicialmente en el trabajo de Gisela Espinosa (2009), quien identifica cuatro vertientes del feminismo en México: feminismo histórico, feminismo civil, feminismo popular y feminismo indígena. A partir de mi propio análisis de los feminismos en Chiapas, encuentro que dentro del feminismo civil hay que distinguir entre aquel impulsado por mujeres de organismos no gubernamentales que no trabajan con los gobiernos locales y estatales y aquel otro que hace trabajo de advocacy, que pueden ser mujeres académicas o de asociaciones civiles. La diferencia es importante porque en Chiapas la consigna de «no trabajar con el gobierno» data de los años ochenta y se reforzó con el levantamiento armado del Ejército Zapatista de Liberación Nacional (EZLN), convirtiéndose en vector de toda una política histórica identitaria.
} 
sitan con dignidad, confidencialidad y profesionalismo». Los objetivos estratégicos que propone son: crear un esquema de coordinación interinstitucional que garantice el acceso a los servicios, articular las acciones de los distintos espacios de atención en el sector público y generar mecanismos de evaluación de los servicios, el personal y la aplicabilidad del modelo.

El segundo es el Modelo Ecológico de Atención a la Violencia Basada en el Género en Ciudades Seguras (Incháustegui y Olivares 2011:9), el cual aspira a ser holístico, esto es, reconoce las diferentes condiciones que subyacen a las prácticas violentas. Basado en los enfoques de Heise y Bronfenbrenner, "parte del supuesto de que cada persona está inmersa, cotidianamente, en una multiplicidad de niveles relacionales —individual, familiar, comunitario y social — en los cuales se pueden producir distintas expresiones y dinámicas de violencia» (Incháustegui y Olivares 2011:21). Factores biosociales que subyacen en la historia personal, el ambiente más inmediato a la persona formado por familia y amistades, los contextos sociales donde tienen lugar estas relaciones, la estructura de la sociedad (la impunidad, la cultura de la ilegalidad) y el momento histórico son los niveles en que tienen lugar las prácticas violentas, de acuerdo con dicho modelo. De manera que el enfoque ecológico «ayuda a identificar las raíces de los fenómenos que impiden, retardan o favorecen el clima de violencia, así como los factores que pueden beneficiar el cambio de los mismos» (Incháustegui y Olivares 2011:26).

La propuesta de acción holística resultante comprende entonces medidas tales como: centrarse en los contenidos educativos y culturales, el desarrollo y la mejora de los servicios de atención a mujeres víctimas de violencia (el modelo también reconoce que personas feminizadas pueden vivir violencia), así como de los servicios de procuración y administración de justicia, la promoción de la cultura de la legalidad y la eliminación de la impunidad, y en políticas que incrementen las oportunidades para la juventud.

Finalmente, el modelo cuenta con criterios de operación: gobernabilidad, cooperación y coordinación entre niveles de gobierno, transversalidad, participación ciudadana, profesionalización del personal y rendición de cuentas. La transversalidad se define como «un método de gestión de políticas intersectoriales, es decir, de aquellas cuyos objetivos de intervención cruzan las fronteras de sectores y organizaciones y que, incluso, pueden involucrar la participación tanto de instituciones públicas como organizaciones empresariales y de la sociedad civil» (Incháustegui y Olivares 2011:71). Dicha transversalidad está en la base de 
la vinculación institucional que haría posible afrontar la violencia de una manera integral, ya que cada institución desempeñaría el papel que le corresponde.

Estos modelos constituyeron un referente nacional a partir de los cuales, en Chiapas, la abogada feminista Martha Figueroa Mier desarrolló una propuesta local: Modelo de Atención a Mujeres en Situación de Violencia (Sedesol et al. 2011), basada en un enfoque de derechos humanos, género e interculturalidad. En este, «romper el silencio» y fomentar la «cultura de la denuncia» se identifican como dos estrategias fundamentales. Este último modelo llamaba ya la atención sobre algunas debilidades del PAIMEF y la importancia de capacitar en varios frentes a las profesionales. El siguiente paso, con la investigación que realicé, fue buscar precisamente la formulación de protocolos regionalizados de atención a mujeres en situación de violencia con el fin de mejorarla. El conocimiento de los idiomas originarios en municipios indígenas por parte de las profesionales destacó como un elemento imprescindible para mejorar el servicio y, al contrario, su ausencia como una debilidad estructural.

El PAIMEF en Chiapas se centraba en aquel momento en la atención, al menos durante el tiempo en que se desarrolló la presente investigación. El trabajo con perspectiva de género que desarrollaban las profesionales en la atención a mujeres víctimas de violencia intentaba ofrecer, de diversas maneras y en niveles bastante diferenciados, aquella visión holística del problema, algo que dependía mucho de sus propias habilidades y capacidades, tanto como de las acciones realizadas por las instituciones gubernamentales. Más allá de las habilidades individuales y del grado en que se apropiaban de la perspectiva de género, en el PAIMEF en Chiapas se buscaba contar con una infraestructura adecuada y segura, así como acompañar al personal involucrado en la atención con programas terapéuticos de contención (las constelaciones familiares, en este caso) (Incháustegui y Olivares 2011:32-44). Todo lo cual indicaría la calidad en la atención a las mujeres, entendida como calidad técnica y calidad humana (Sedesol et al. 2010:4).

Para el año 2012, el PAIMEF contaba con 20 unidades y una ventanilla única (Tuxtla Gutiérrez) en igual número de municipios. Su ubicación geográfica abarca diferentes microrregiones del estado en la idea de tener un radio de acción estatal significativo.

Si una de las limitaciones más importantes del Instituto Estatal de las Mujeres de Chiapas fue, desde el inicio, su bajo presupuesto, en el caso del PAIMEF cuenta con recursos federales, con lo cual el aspecto financiero no constituye tanto problema, si bien el largo trámite administrativo por el que pasan los recursos 
antes de poder disponer de ellos ocasiona que el personal no pueda recibir su salario hasta mediados de cada año. En las diversas entrevistas se constató que el servicio no deja de ofrecerse, en el primer semestre del año, por esa razón. En cualquier caso, no es irrelevante la dinámica burocrática que no resuelve con prontitud trámites administrativos necesarios para proveer los recursos de modo oportuno; incluso el desvío de recursos como posibilidad o realidad está presente en la administración pública del estado. Esos factores han incidido en la decisión de mujeres formadas en género en organismos no gubernamentales de renunciar a sus cargos dentro de la administración pública (entrevistas a García y Revilla 2012).

Un insuficiente presupuesto gubernamental orientado a mujeres, sumado a dinámicas institucionales burocratizadas que alejan de continuo a mujeres con formación en género involucradas directa o indirectamente en las estructuras gubernamentales, son factores que debilitan las políticas de transversalización de género.

En el caso del PAIMEF, las limitaciones materiales se evidencian también de otra manera. La lucha por los espacios ha sido sin duda la más fuerte de las problemáticas enfrentadas en los últimos tiempos, ya que las unidades son cambiadas de un domicilio a otro por las administraciones municipales. En particular, ha sido difícil conseguir, de acuerdo con el modelo de atención, oficinas que tengan dos lugares, uno para cada servicio proporcionado, legal y psicológico, para así garantizar privacidad a las usuarias. De las 18 unidades que conocí, ocho se encontraban en condiciones óptimas, es decir, tenían una oficina propia, en el mejor de los casos con dos lugares, una buena ubicación en términos de acceso a las usuarias y el mobiliario indispensable; tres unidades contaban con oficina propia, pero sin las condiciones adecuadas en términos de ubicación, ventilación, iluminación, etc.; cinco no tenían oficina propia, sino que era compartida con otras instancias municipales. Finalmente, una unidad tenía una situación que llamé crítica porque no garantizaba siquiera la seguridad de usuarias y profesionales.

En tales condiciones materiales, los servicios básicos que se ofrecen son la canalización, las asesorías (legales y psicológicas) y el acompañamiento, entendido este como el apoyo moral, las terapias y permanecer al lado de las usuarias en todo este proceso jurídico.

Al observar el PAIMEF en su funcionamiento $-\mathrm{y}$ lo mismo cabe decir respecto de quienes dirigen las Instancias Municipales de Mujeres - podemos afirmar que estamos ante una nueva generación de mujeres, la mayoría de ellas chiapane- 
cas menores de 35 años, que no han sido formadas centralmente por feministas y organismos no gubernamentales con larga trayectoria en el estado ni menos aún —en el caso de las mujeres indígenas - por la Coordinadora Diocesana de Mujeres (Codimuj) de la Diócesis de San Cristóbal de Las Casas (en la llamada Teología de la Liberación y, más recientemente, Opción por los Pobres). Más que hablar de un relevo generacional en marcha, observo que la política transversal de género de la federación hacia los estados ha contribuido a ensanchar las fronteras del trabajo con mujeres desde una perspectiva de género limitado anteriormente a los organismos civiles de la entidad. Política que en el PAIMEF, al momento de hacer la investigación, se veía favorecida por las coordinadoras al frente, como señalé antes.

La formación con perspectiva de género entre las profesionales, por tanto, estaba en proceso. Un buen indicador al respecto era el uso de la categoría de género para explicar los cambios en su propio ser como mujer y como profesional ayudando a otras mujeres: las ha cambiado a ellas mismas - como lo expresan-y las ha hecho sensibles en el acompañamiento a las usuarias. Refieren que la labor con víctimas de violencia las hizo reflexionar sobre sus vidas familiares - como hijas o como madres-, es decir, ha tenido un impacto positivo en ellas. Se reconocen como personas que también ejercen violencia, usualmente contra los hijos y las hijas, u otros miembros de la familia, por lo cual ellas mismas deben transformar sus prácticas cotidianas.

Además, el trabajo de género en el PAIMEF posibilita que la labor directa con mujeres genere empatía y compromiso, al punto de tomar el trabajo no solo como un medio de vida sino también un modo de vida. ${ }^{8} \mathrm{El}$ hecho de que las abogadas usen su propio dinero para los traslados a juzgados y ministerios es tan solo el ejemplo más palmario del interés y el compromiso adquiridos. Hay algunos indicadores más que me dieron pauta para pensar en la empatía y el nivel de compromiso, entre ellos, el hecho de que durante los primeros seis meses de cada año las profesionales no cobran su salario, sino que tienen que esperar hasta julio, aproximadamente, para percibir el monto total (esto por la dinámica burocrática antes explicada). Además, algunas profesionales han tenido otras opciones laborales en el mismo municipio o en otro lugar y han optado por que-

8 Desde una perspectiva de varios años, hombres abogados y psicólogos al frente de las unidades fueron remplazados progresivamente por mujeres, lo que ha dado mayor confianza a las usuarias, según revelan las entrevistas. Por otro lado, solo en un caso, una abogada de la ventanilla única de Tuxtla Gutiérrez se vio forzada a renunciar en 2012 frente a las quejas de usuarias. Una de tales quejas la recogí yo misma, directamente, en la entrevista a una usuaria en la unidad de Villaflores. 
darse en el PAIMEF. Y aunque han sido amenazadas por hombres del municipio vinculados familiarmente a las mujeres que acuden al PAIMEF, tampoco ha sido suficiente razón para la renuncia laboral.

Otro importante indicador de cómo la perspectiva de género ha ayudado en la labor de las profesionales es el trabajo con las usuarias en la comprensión y explicación de la violencia en el contexto de relaciones sociales de subordinación y poderes arraigados en la cultura; una perspectiva de género, si se quiere, en un nivel muy básico, pero que representaba una diferencia significativa entre el servicio que ofrecían desde el PAIMEF frente a aquel otro ofrecido en el Desarrollo Integral de la Familia (DIF), las oficinas regionales de la Procuraduría General de Justicia del Estado (PGJE) y del Ministerio Público.

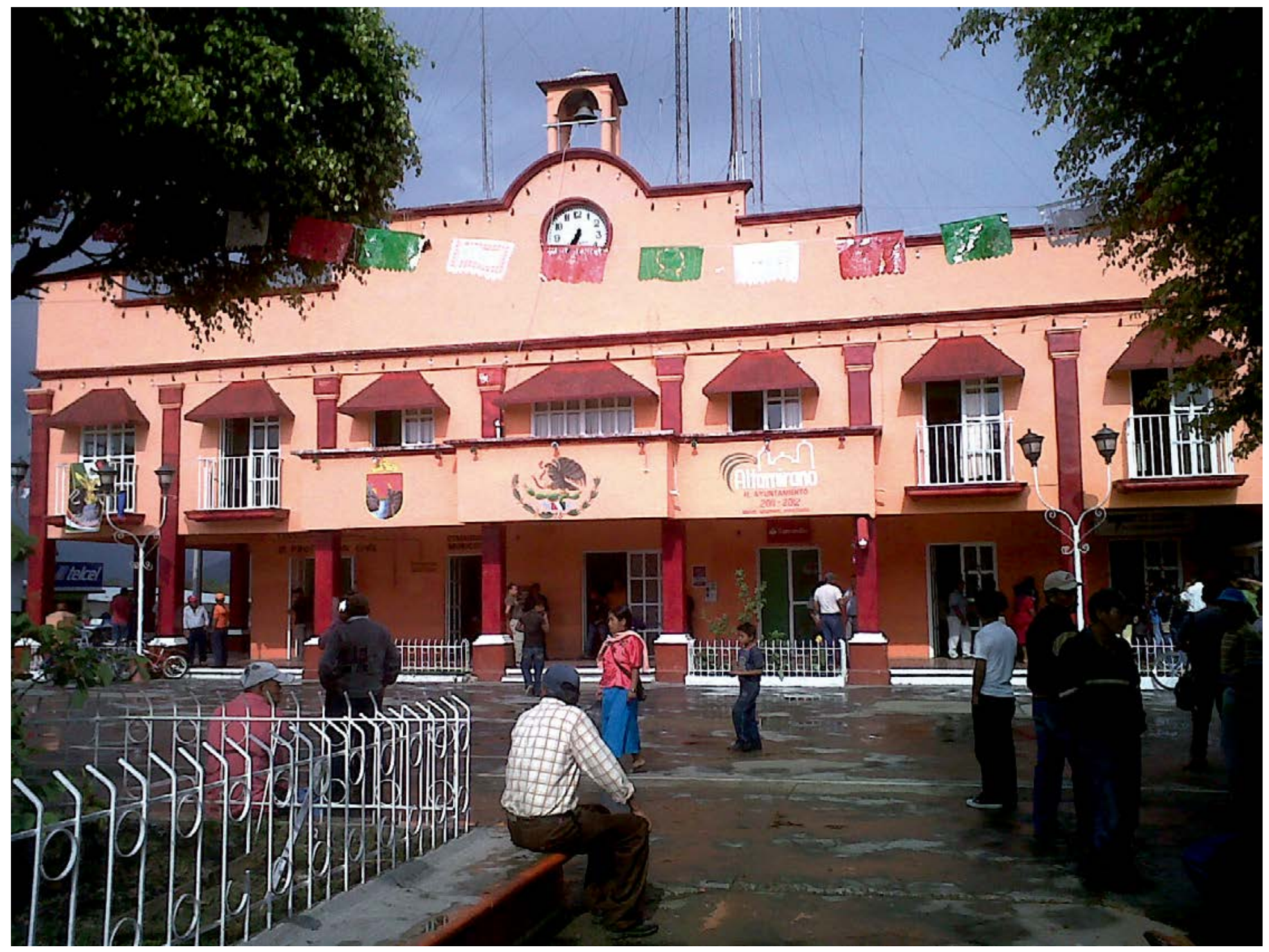


La permanencia de las profesionales en las unidades se convertía así en un capital social significativo del Programa. ${ }^{9}$

No vi, sin embargo, y esto es una importante debilidad en la formación con perspectiva de género, que las usuarias conocieran y reforzaran su experiencia como el derecho a una vida libre de violencia, como tal, lo que tenía que ver posiblemente con la formación en género todavía en proceso de las profesionales. Este aspecto fue una de mis observaciones concretas a las coordinadoras del PAIMEF sobre el trabajo realizado por las profesionales y que debería trabajarse a fondo.

Por otro lado, dado que las unidades están ubicadas en las cabeceras municipales, la mayoría de las usuarias son sus habitantes y en un número mucho menor provienen de comunidades y localidades. Si bien las unidades se conciben en términos regionales, pocas de las que viven fuera de la cabecera buscan el servicio, a juzgar por las profesionales.

Todas esas condiciones generales ya nos empiezan a hablar del alcance y las limitaciones del programa, así como de la calidad en la atención a mujeres en situación de violencia, en un continuum que va de muy buena a baja. Sin embargo, pese a todas las limitaciones, usuarias locales, rurales y urbanas, mujeres indígenas y centroamericanas acuden al servicio y lo califican favorablemente.

\section{LEYES Y FAMILIA VERSUS EL DERECHO A UNA VIDA LIBRE DE VIOLENCIA}

Como señala Rodríguez (2009), a partir de la reforma al artículo 115 constitucional, los gobiernos locales asumen tareas de mayor complejidad frente a los problemas del desarrollo; junto a ello, las llamadas reformas de tercera generación, centradas en la democratización política, la ampliación de la participación ciudadana y el ejercicio de derechos, inciden en la adopción de las políticas de igualdad en este nivel de la administración pública. En Chiapas, las Instancias Municipales de Mujeres — con diversos nombres en los municipios - tienen su base en la Ley Orgánica Municipal (Gobierno del Estado 2010), cuyo artículo 36, párrafo LXVII, señala la necesidad de:

\footnotetext{
9 Para afrontar en mejores condiciones los casos de violencia, las profesionales se apoyan con terapias individuales que pagan con sus propios ingresos, y en el trabajo colectivo en talleres de contención emocional organizados por la coordinación estatal.
} 
Crear un área encargada de fomentar y vigilar la equidad de género, en todos los ámbitos y niveles de decisión de la Administración Pública Municipal, garantizando el respeto mutuo, la superación igualitaria y la convivencia armónica entre la mujer y el hombre, a fin de que los programas municipales, se alineen a los Objetivos de Desarrollo del Milenio, conforme al presupuesto de su ejercicio.

El 14 de septiembre de 2011 se reformó la Ley de Acceso (Art. 3) para establecer en sus disposiciones generales que el estado y los municipios tomarían medidas presupuestales y administrativas para garantizar a las mujeres el derecho a una vida libre de violencia. Pero en los hechos ni el PAIMEF ha cumplido en el sentido de apoyar, en principio, a las Instancias Municipales, ni los ayuntamientos han asumido un papel más activo en la atención de la violencia.

De acuerdo con una investigación (Castro 2010), si bien en la letra hay Instancias de mujeres en los 121 municipios del estado, en algunos lugares existían solo de nombre, ya que no operaban cotidianamente, o bien la dirección era ocupada por alguna regidora en turno, lo cual reflejaba la baja institucionalidad de la instancia en la estructura del gobierno municipal. Las Instancias en todo caso han solido estar formadas por una sola persona, con percepciones salariales no homologadas (es decir, que las mujeres en un cargo público determinado ganan menos que los hombres en el mismo nivel jerárquico) y sin contar con más personal capaz de ofrecer el apoyo legal, psicológico o de trabajo social (ciertamente, por esta razón el PAIMEF se concibe para fortalecer dichas Instancias, pero no siempre tienen buena vinculación). Algunas mujeres al frente de las Instancias asumían su papel de dirección de la mejor manera posible, a veces reproduciendo roles de género tradicionales, lo que se expresaba en el fomento de la impartición de talleres de costura y tejido que consideraban «idóneos» para la población femenina, mientras otras solían limitarse a la labor de canalización. Esta última labor se entiende como asesorar a las mujeres respecto de cuáles instancias y personas pueden apoyarlas en los problemas planteados y, en su caso, acompañarlas.

Independientemente de las labores desempeñadas, casi invariablemente se realizaban en condiciones de escasez continua, por no contar con un presupuesto propio, y debido al poco interés mostrado por las autoridades locales en turno en lo tocante a las propias Instancias. Y nuevamente el problema del espacio: las oficinas que ocupaban, cuando las tenían, eran modestas y con el mobiliario que les había sido proporcionado por medio del Programa de Fortalecimiento a las Instancias Municipales de Mujeres (Fodeimm), si acaso. El estudio regional de Rodríguez (2009:347-354) coincide en varios de los puntos planteados, pero ade- 
más señala que los procesos de diseño del Plan Municipal de Desarrollo ocurrían sin la participación de las directoras de las Instancias. Además, desde las propias instancias tampoco se habían realizado informes de actividades o procesos de evaluación de las acciones emprendidas hasta ese momento.

En ese contexto, no resulta difícil entender por qué el PAIMEF se pone en operación en las condiciones materiales antes señaladas, sin un vínculo fuerte con las Instancias de la Mujer. Precisamente, uno de los problemas centrales que afrontan las profesionales en el desarrollo de su trabajo es la débil vinculación institucional, con las excepciones de la ventanilla única de Tuxtla Gutiérrez (ubicada dentro del Centro de Justicia de Mujeres) y la unidad de San Cristóbal de Las Casas.

En particular la excepcionalidad de la unidad de San Cristóbal puede deberse a varios factores, entre ellos, al hecho de que quien estaba al frente de la Dirección de Equidad de Género del ayuntamiento era una mujer con trayectoria profesional en organismos no gubernamentales, con larga experiencia en atención a mujeres en situación de violencia, lo que, en principio, puede proporcionar una sensibilización de género y mayor disposición para afrontar las problemáticas en este ámbito público, conjuntamente con el PAIMEF. Además, en aquel momento había en el cabildo una regidora de un partido político de oposición interesada en los problemas de género, con quien se podían hacer alianzas estratégicas. ${ }^{10}$ Para mayor ventaja, San Cristóbal es una ciudad donde se asientan numerosos organismos no gubernamentales que directa e indirectamente hacen trabajo con mujeres y con perspectiva de género, atentos a las violaciones de los derechos humanos y muy activos políticamente. En este contexto, la vinculación institucional era bastante favorable en la resolución de casos, como pudo notarse en el año 2012 frente al feminicidio de Ixchel, joven indígena tseltal, en cuyo seguimiento y esclarecimiento colaboraron todos aquellos actores.

Sin embargo, se trata de excepciones a la regla. De hecho, lo que pude constatar es que las profesionales de la mayoría de las unidades no eran bien «vistas» en el marco institucional local porque «se mandan solas» y no son vistas como personal del propio ayuntamiento. Las profesionales han tenido que explicar a las autoridades que sus funciones no son las que busque indicar la directora del DIF o cualquier otro funcionario del ayuntamiento. Esto no significa que no realicen otras actividades, como la difusión del Programa en los medios de comunicación

\footnotetext{
10 Esta perspectiva fue recuperada mediante una entrevista a la directora de Equidad de Género en turno, en el gobierno municipal de San Cristóbal de Las Casas, agosto de 2012.
} 
(en Oxchuc se cuenta con un programa de radio en tseltal) y la misma impartición de talleres en las comunidades que les han solicitado algunas autoridades locales, pero la labor prioritaria es la atención a víctimas en las unidades respectivas.

La percepción de que «se mandan solas», en realidad, es recíproca, ya que las profesionales se saben «independientes» del ayuntamiento municipal con el deber de responder exclusivamente frente a la coordinación estatal del PAIMEF, y la refuerzan tomando decisiones sin consultarlas o compartirlas con las autoridades locales. Naturalmente, la débil vinculación institucional, como ya hemos visto, impacta negativamente en las condiciones materiales y en el momento de buscar difundir el PAIMEF en las comunidades, tal como lo señala una profesional: «y por los ayuntamientos que no hay apoyo a nosotras, por lo mismo que somos autoridad independiente, veo que no hay esa facilidad para ir [a las comunidades] a presentarnos y explicar [a las mujeres] cuáles son sus derechos, que no tengan miedo ya de ser amenazadas por su pareja» (Unidad Altamirano, entrevista, octubre de 2012, subrayado mío).

Por otro lado, las autoridades municipales observan críticamente que las profesionales «sólo atienden a mujeres», cuando «el problema está en atender a toda la familia» y también a los hombres. ${ }^{11}$ En el municipio de Tenejapa las autoridades municipales ven al PAIMEF y a las profesionales como «parciales» por esa razón; una parcialidad que se supone problemática y hasta conflictiva de cara a la preservación de la familia. Mujeres jóvenes todas ellas, las profesionales, con una labor permanente y de gestiones continuas en las instancias municipales -es decir, su trabajo es visible y apoyado por las usuarias-, aparecen incluso como «mujeres que quieren mandar» a las propias autoridades, según estas mismas.

En conclusión, si bien con gradaciones distintas entre las unidades, la vinculación institucional era débil. Durante la investigación se advirtió que una causa importante de esta situación era el poco conocimiento que las autoridades municipales tenían del PAIMEF, una responsabilidad que atribuyo a las profesionales de la coordinación del programa, pero sobre todo a la propia SEDEM estatal. Una de las propuestas que hice entonces para intentar remediar la situación de desconocimiento de los alcances del programa y del impacto en la vida de las mujeres y sus familias por parte de las autoridades fue dar a conocer el PAIMEF en reuniones especiales con las autoridades entrantes a partir de octubre de $2012 .^{12}$

\footnotetext{
${ }^{11}$ Entrevistas a presidente municipal de Huixtán, diciembre 2012; y a la directora del DIF municipal en Frontera Hidalgo, noviembre de 2012.

12 Las elecciones para renovar gubernatura, presidencias municipales, cabildos y congreso local se realizaron en Chiapas el 6 de julio de 2012, simultáneamente al Proceso Electoral Federal 2011-
} 
Este último caso se planteó en el municipio de Oxchuc, durante la entrevista con funcionarios locales: que el ayuntamiento se encargue del pago de las profesionales del PAIMEF. No está de más mencionar que un factor favorable para esta buena recepción fue que dos de ellos ya habían colaborado en el PAIMEF estatal y federal, ${ }^{13}$ y sabían tanto de las dificultades administrativas que afronta como del impacto positivo que tiene en la vida de las mujeres y sus familias.

Adicionalmente, en la interlocución continuada con las autoridades un componente tendría que ser el redimensionamiento del problema de la violencia en los hogares como algo que padecen fundamentalmente las mujeres, los hijos y las hijas, y cuya solución beneficia a la familia en su conjunto. Es un problema vinculado en muchos lugares con el consumo de alcohol, pero siempre ligado a una fuerte confianza y creencia sociales respecto de la expresión del dominio masculino a través del ejercicio continuado de la violencia.

Figueroa (Sedesol et al. 2011:9) señala que una de las dificultades para el abordaje de la violencia es la naturalización del problema, es decir, «dado el modelo de relaciones familiares que se han construido socialmente, la violencia como forma de relación es vista como natural». En entrevistas con autoridades ciertamente encontré diferentes resistencias, al lado del aura moral que tiene «la familia» y su preservación por encima de cualquier problema. Y no parece fácil remontarlas en un contexto donde predominan ideas como esta expresada por un alcalde:

Pero ¿qué pasa ahí? ¿Qué pasa? ¿Cómo trabajan los valores? Porque ahí tiene que ver mucho los valores, todo lo de la desintegración familiar, la violencia familiar, el incumplimiento de la pensión alimenticia. Cómo estos valores se tienen que trabajar. Porque de ahí, la integración familiar es super valiosísima, pero, ¿desde qué será? Desde una responsabilidad compartida. Porque a veces la mujer es la que manda y la mujer es la que quiere mandar. Entonces se generan conflictos (Alcalde, octubre de 2012, subrayado mío).

2012. La presentación del PAIMEF se hizo entre octubre y diciembre de 2012 en ocho presidencias municipales —con el presidente, o bien otras autoridades_en Huixtán, Tenejapa, Oxchuc, Yajalón, Tapachula, Frontera Hidalgo, Tuzantán y Pichucalco. En la presentación del Programa estábamos presentes las profesionales de las Unidades respectivas, la subcoodinadora de Seguimiento de las Unidades y yo.

13 Entrevistas con Natanael Reyes, funcionario de Oxchuc y ex administrador estatal del PAIMEF, y Eduardo Rivera, funcionario de Oxchuc y ex coordinador administrativo del PAIMEF en Indesol (Oxchuc, noviembre de 2012). 


\section{LA ATENCIÓN A MUJERES INDÍGENAS: FRONTERAS LINGÜÍSTICAS Y CULTURALES}

A la débil vinculación institucional "desde arriba», a nivel estatal, que impacta negativamente en la mayoría de las unidades del PAIMEF, en las ubicadas en territorio indígena se suman dos elementos que afectan la atención a mujeres en situación de violencia: las concepciones y prácticas en los Juzgados de Paz, pero también el desconocimiento de los idiomas originarios por parte de las profesionales.

Entrevisté a dos mujeres indígenas tojolabales (Las Margaritas), dos zoques (Jitotol y Tecpatán), una tsotsil (Jitotol) y siete tseltales (Altamirano, Huixtán, Oxchuc y Tenejapa), seis de ellas con poco dominio del español y casi todas con la demanda de pensión alimenticia. Entre las mujeres indígenas se dan más casos de solicitud de pensión alimenticia y/o reconocimiento de paternidad, y pocos casos en los que se busca reconocer y afrontar la situación de violencia que viven.

Siete unidades están ubicadas en territorios con población predominantemente indígena: Altamirano, Huixtán, Las Margaritas, Ocosingo, Oxchuc, Jitotol y Tenejapa. Mientras tanto, San Cristóbal de Las Casas puede contarse en este grupo por el fuerte crecimiento de la población originaria, que la ha hecho merecedora del título de «ciudad de indios». Con excepción de Ocosingo (región XII Selva Lacandona), Las Margaritas (Región XV Meseta Comiteca Tojolabal) y Jitotol (Región VII De los Bosques), los otros son parte de la Región V Altos Tsotsil-Tseltal. El personal indígena al frente de las Unidades en estos últimos municipios no se cubre satisfactoriamente, lo cual constituye una importante debilidad en la atención. ${ }^{14}$ De las nueve unidades, solo en tres había abogadas indígenas (Altamirano, Las Margaritas y Tenejapa) y en dos había psicólogas indígenas (Oxchuc y San Cristóbal). Si el trabajo de abogacía se realiza con instituciones municipales, regionales y estatales, lo que exige el conocimiento preciso del español y, en algún sentido, se puede prescindir de los idiomas originarios, no ocurre lo mismo con las terapias psicológicas.

El trabajo de las profesionales mestizas en unidades indígenas me reafirmó la convicción de que la reflexión sobre la psicología como ciencia de matriz occidental, sus alcances y limitaciones en otras latitudes, en particular las terapias psicológicas individuales entre la población indígena como una herramienta para

14 González y Valdez (2008:444), en su análisis sobre la metodología seguida para la aplicación de la Encuesta Nacional sobre Salud y Derechos de las Mujeres Indígenas en 2007, señalan que en la región Altos fue donde más se requirió la traducción al momento de aplicarla. 
las víctimas de violencia, es todavía un ámbito por explorar. Lo que queda claro es que el servicio psicológico exige una relación en todo caso basada en una comunicación fluida y precisa, así como de conocimiento del terreno y de la cultura. Sin demeritar el trabajo psicológico realizado, lo menos que podemos esperar es que se haga en el idioma de las mujeres en situación de violencia, lo que debería ser un requisito de contratación.

Este panorama, junto al hecho de que sean en su mayoría usuarias de las cabeceras municipales, me llevó a proponer las Unidades Itinerantes del PAIMEF. En estas las profesionales tendrían que ser hablantes de idiomas indígenas, y son itinerantes porque se trasladarían continuamente de municipio a municipio, visitando comunidades aisladas del centro municipal. ${ }^{15}$

El otro elemento a considerar en la atención a mujeres en situación de violencia en las unidades de Altamirano, Huixtán, Oxchuc y Tenejapa es la práctica de los Juzgados de Paz y Conciliación. Dichas instancias operan desde finales de los años noventa del siglo pasado y fueron creadas por iniciativa del gobierno estatal en turno. Antes de las modificaciones legales ya funcionaban los juzgados municipales, donde se supone se practicaban mecanismos tradicionales; ${ }^{16}$ de particular mención está la «conciliación» que se sigue practicando en los Juzgados de Paz.

Para contextualizar tal estrategia, hay que hacer referencia brevemente a la discusión sobre los llamados «usos y costumbres» indígenas. En el contexto del levantamiento armado del Ejército Zapatista de Liberación Nacional (EZLN) y las negociaciones sobre los Acuerdos de San Andrés, los usos y costumbres se debatieron favorablemente en diversos ámbitos académicos y políticos, si bien también hubo rechazos al término porque se considera que refleja subordinación al sistema nacional (Carlsen 1999), de modo que se usan otras nominaciones como derecho indígena, derecho consuetudinario o costumbre jurídica indígena (Rus 2000, Valdivia 1994, Dorotinsky 1990). ${ }^{17}$

15 Las unidades propuestas fueron: Unidad Tseltal, Unidad Tsotsil, Unidad Tojolabal, Unidad Ch'ol y Unidad Mestiza (Castro, 2012b:12-13). Cómo dar seguimiento a casos determinados sería un punto a definir porque no es lo mismo tener una oficina fija que una itinerante con la que una mujer en situación de violencia no siempre ha de contar; el tiempo de estancia de las unidades itinerantes en las comunidades y cómo deberían hacer sus recorridos serían otras cuestiones por definir en el escenario de su creación.

16 En Oxchuc, tanto el cabildo como el Juzgado de Paz y Conciliación atienden tales casos de violencia (Cameras 2013).

17 Valdivia (1994) identifica tres elementos que definen la costumbre jurídica indígena: normas jurídicas, autoridades y procedimientos; las primeras son reglas obligatorias de comportamiento que imponen deberes y confieren derechos, preceptos todos ellos que se suponen inscritos en la 


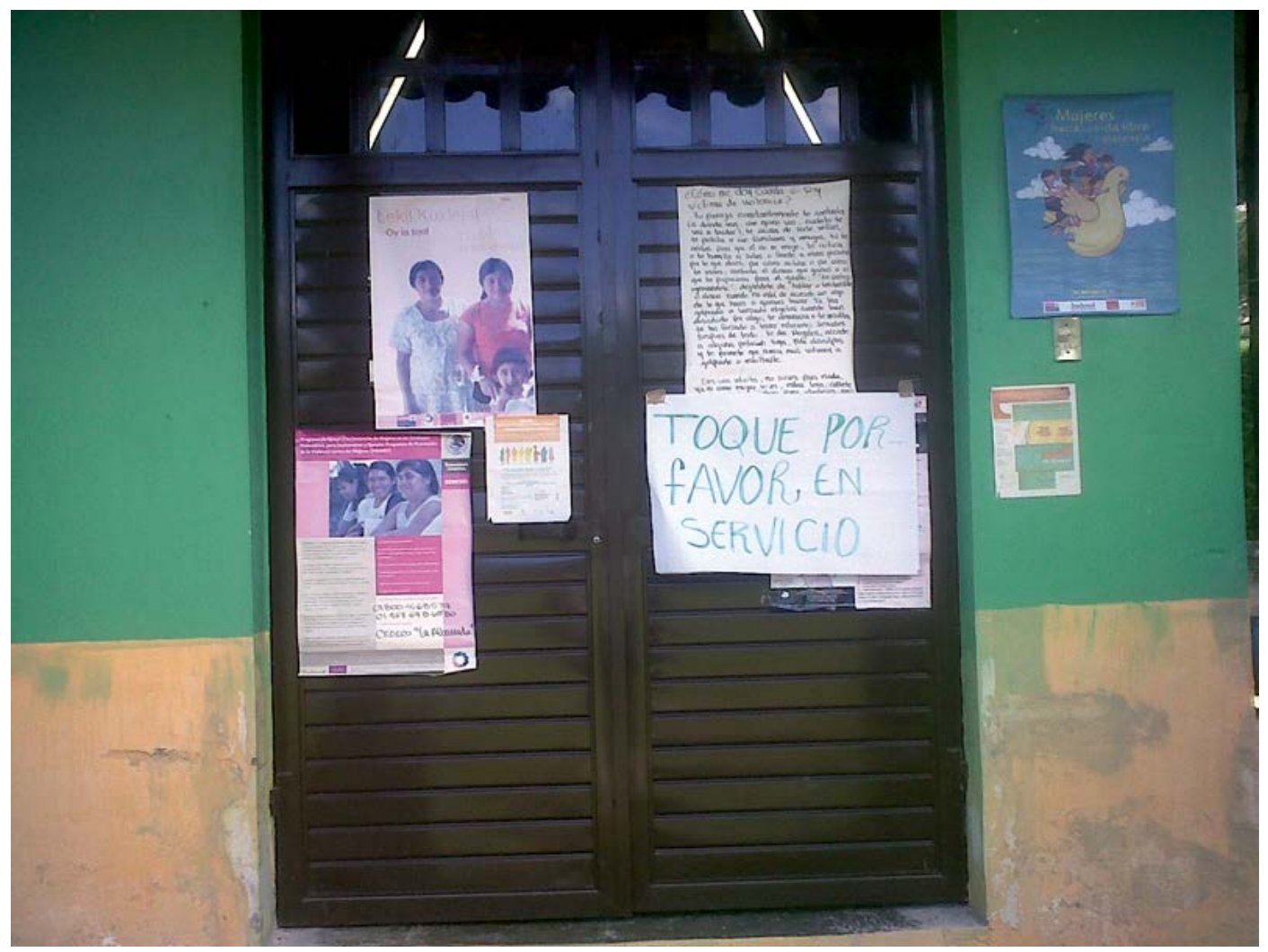

Los Juzgados de Paz tienen atribuciones y facultades que son prácticamente las mismas que las de los juzgados municipales (se ocupan de asuntos «menores» o, como prefiere llamarlos Anna María Garza, cotidianos), con una estructura en todo caso más estrechamente imbricada con la del poder judicial y, por tanto, con menor margen de autonomía. Anna María Garza (2002) documentó casos llevados en los juzgados municipales que revelan en su funcionamiento relaciones de poder y reproducción de las desigualdades. El llamado «consenso» refuerza de hecho las jerarquías entre hombres y mujeres, y entre jóvenes y personas adultas. Del conjunto de 199 actas del juzgado revisadas, la autora encontró que casi la tercera parte correspondía a disputas de pareja y en las que la mujer buscaba separarse del cónyuge: problemas de violencia doméstica, de irresponsabilidad económica, abandono, poligamia, así como desavenencias entre la pareja y otros miembros de la familia extensa. En tales casos es frecuente que los jueces den consejos a las partes involucradas sobre lo que es una «buena» mujer, un «buen» marido y las obligaciones a cumplir por cada

memoria colectiva. Los procedimientos se refieren a las formas mediante las cuales se ejerce la ley (por las autoridades) y las autoridades tradicionales se encargan de dirimir controversias internas y tomar decisiones sobre la vida comunitaria. 
cual. De manera que de las mujeres se espera que cumplan con todas las tareas domésticas y obedezcan a su marido y a sus suegros; mientras tanto, al hombre se le pide que trabaje, provea a su familia de lo que necesita para vivir y respete y ayude a sus mayores.

En materia de atención a mujeres en situación de violencia, por tanto, en los juzgados municipales y ahora en los Juzgados de Paz la conciliación se traduce en los hechos en la voluntad de evitar la separación de la pareja, por encima de cualquier cosa. Esta es la experiencia repetida que las profesionales del PAIMEF afrontan en los municipios indígenas, de manera que, si bien la Ley de Acceso en su reforma de 2011 establece que la violencia no es conciliatoria, la atención en estas unidades se contrapone a la estrategia de los jueces indígenas.

No deja de ser relevante poner a discusión que, dado que ha habido casos de víctimas que en los propios ministerios públicos encuentran esta recomendación («piénselo bien, luego las mujeres vienen otra vez porque se arrepienten de poner la demanda contra el esposo»), no parece tanto una característica exclusiva de los Juzgados de Paz y podría dar cuenta, más que de un pretendido rasgo cultural, de una concepción misógina profundamente arraigada que acuerpa la dominación masculina en diversas sociedades. ${ }^{18}$

Por otra parte, las abogadas del PAIMEF tienen una experiencia diferenciada que es importante resaltar. Mientras las abogadas mestizas de Huixtán y Oxchuc y la abogada indígena de Tenejapa habían tenido malas experiencias en su vinculación con el Juzgado de Paz ante casos de violencia contra mujeres, la abogada tseltal en Altamirano habló de su buena coordinación con las instancias municipales. Ella fue procuradora en San Juan Cancuc, Chanal y Oxchuc antes de entrar al PAIMEF y en este marco su experiencia con el Juzgado de Paz la calificaba como buena, ya que, por ejemplo, tuvo las facilidades para recorrer las comunidades y en los casos de reconocimiento de paternidad y, por tanto, pensión alimenticia, la vía de la conciliación era la más rápida. En este caso la conciliación se refiere a que los jueces convencen al hombre para que reconozca la paternidad sobre un infante y sobre una determinada cantidad de pensión alimenticia

\footnotetext{
${ }^{18}$ En tal sentido, coincido con Figueroa (Sedesol et al. 2011:24-25) en que el derecho indígena no es un espacio al margen de la ley, por lo que «es importante escuchar lo que las mujeres indígenas tienen que decir sobre la 'tradición', y saber que es la oportunidad de deconstruir mitos y prácticas culturales que afectan la vida diaria de todas las mujeres».
} 
(usualmente muy baja, dicho sea de paso). Seguir este tipo de casos por el juzgado civil implicaría que la solución tomase hasta un año o más. La abogada resaltó el hecho de que la buena coordinación había sido posible porque hablaba tseltal; es posible, sin embargo, que el hecho de trabajar en instancias identificadas como parte del gobierno municipal haya sido un factor coadyuvante, ya que le había permitido conocer de cerca las dinámicas institucionales locales.

\section{LAS VOCES DE LAS USUARIAS: \\ «QUE EL PROGRAMA SIGA, QUE HAYA APOYO PARA NOSOTRAS»}

Cada vez es más frecuente que las mujeres víctimas de violencia acudan a solicitar servicios de atención. Diversas son las razones que las llevan a preguntar y solicitar ayuda de algún tipo, si bien pocas buscan servicios de atención a la salud mental (Tiburcio et al. 2010), sea por desconocimiento o por vergüenza. El PAIMEF ha resultado así un programa exitoso desde el punto de vista de la identificación, por parte de las usuarias, de un lugar donde «se puede recibir ayuda». El conocimiento del servicio se da, a juzgar por las entrevistadas, de voz en voz, es decir, una vez que una mujer lo recibe lo comenta con amigas, familiares y conocidas y se da el fenómeno de la bola de nieve.

Para las usuarias, tener como un referente al PAIMEF constituye, de por sí, un aliciente: "ahí te van a ayudar», "ahí hay unas licenciadas que apoyan a las mujeres». Incluso las usuarias pueden referir la existencia del PAIMEF en su defensa frente a la posibilidad de violencia o de su reiteración: «Hay alguien que me defiende». Las usuarias se sientan "protegidas», acompañadas y apoyadas en general, algo que no han encontrado en otras instancias.

Gracias a Dios, yo abrí los ojos y, la verdad, esto bastante me sirvió. Sí, porque, mire usted, ahí está el resultado; para mí ahí está ya el resultado. De mi hija lo mismo; así es. Pues qué

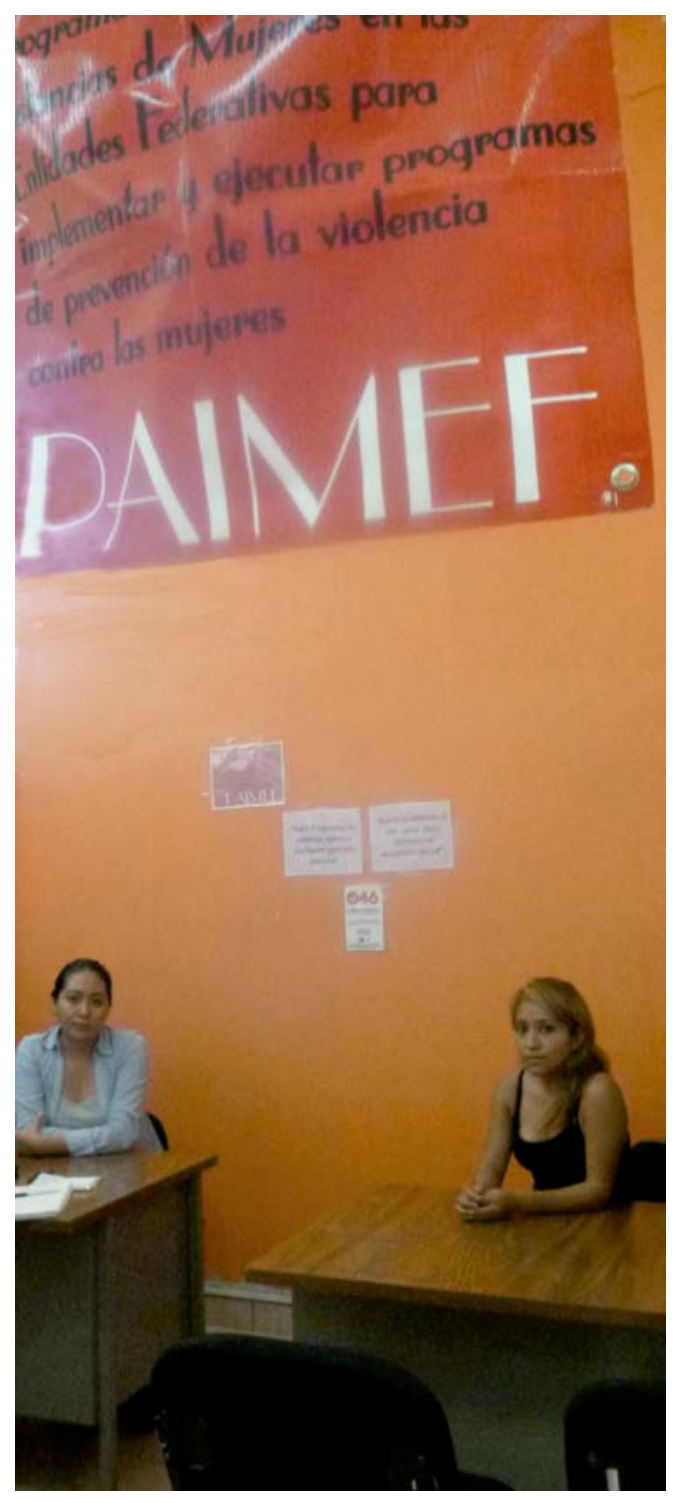


bueno que nunca terminara, pues, este tipo de programa, para mucha gente; más ahorita, ahorita hay mucha violencia, hay mucho maltrato a la mujer, hacia los niños... Sí, entonces, estos tipos de ayuda nos ayudan mucho a mejorar (Las Margaritas, usuaria).

Todas ellas coinciden en la importancia de poder contar con este servicio "gratuito" por el que no pagan nada, ${ }^{19}$ un dato que todas las mujeres resaltan debido a su posición socio-económica: pertenecer a familias con escasos recursos e incluso no contar con vías de financiamiento propias por carecer de un empleo remunerado. La inmensa mayoría de las usuarias entrevistadas tenía, ciertamente, un bajo nivel escolar que en el mejor de los casos no superaba la secundaria o la preparatoria (solo tres contaban con estudios de licenciatura) y no tenían trabajo remunerado.

Estos indicadores, y el hecho de que todas tenían hijos y/o hijas, me llevó a configurar un perfil femenino para el cual la familia lo es todo. Y lo era al punto de que varias abandonaron los estudios, o el trabajo remunerado, al unirse en matrimonio y aun antes de concebir hijos. De modo que la dependencia económica de la víctima con el agresor es un factor presente, tanto como la dependencia emocional, y ambas se refuerzan mutuamente. Así, el empoderamiento, o en sus palabras: «agarrar fuerza», hacer ver en la familia «a una mamá que ya empezó a buscar una vida diferente» no solo es un indicador del cambio sino un paso necesario tanto para la separación como para la transformación en otros niveles.

Las terapias psicológicas suelen ayudar a las usuarias para sentirse empoderadas en algún nivel, para identificar «los diferentes roles que una juega, como madre, como esposa, pero también como mujer» con valor propio. La perspectiva de género puede reducirse aquí a elaboraciones teóricas básicas pero que tienen un importante efecto en la autoestima y en el ánimo de rehacer la vida propia en algún nivel. Hace una importante diferencia el reconocimiento de las mujeres al verse como personas con valor por ellas mismas y con el poder de emprender acciones nuevas que las hagan restructurar sus vidas, lo que se hace evidente particularmente entre aquellas usuarias que han recibido el servicio por varios meses y años.

Tener valor y tener poder se expresa y traduce en tomar decisiones de modo autónomo, independientemente de la pareja. El impacto positivo de la atención a víctimas de violencia puede observarse, ciertamente, en la decisión de la mujer de separarse, pero esto siempre es una decisión propia y como tal se asume en

19 En el trabajo de las profesionales se intenta hacer ver a las mujeres que gracias a los impuestos de la ciudadanía el servicio del PAIMEF es posible. 
el PAIMEF. Es decir, el acompañamiento no las conduce necesariamente a la separación con el cónyuge agresor pero, como lo reconocen algunas, cuando este es el caso sus vidas han cambiado, porque la violencia ya no está presente o porque cambian su condición de víctimas en el hogar, se empoderan en un grado que les permite negociar, posicionarse mejor mostrando que «han cambiado» y que alguien las «defiende». ${ }^{20}$

El conocimiento de los tipos de violencia es ya, ciertamente, un valor reconocido por las usuarias y el inicio de un proceso que puede durar meses o años. En el marco del servicio, y siguiendo la Ley de Acceso, se habla a las usuarias de los diferentes tipos de violencia (violencia física, psicológica, sexual, patrimonial, económica, moral, obstétrica y de los derechos reproductivos) que se ejerce sobre ellas y sus familiares, lo que constituye uno de los principales aprendizajes que tienen porque usualmente asocian el sufrimiento físico a la única violencia existente. Entonces encuentran que puede ser mayor la violencia moral y la violencia psicológica, o tan destructivas como la primera; la violencia económica y la violencia patrimonial no se conocían como tales ni mucho menos la violencia obstétrica y la violencia de los derechos reproductivos. ${ }^{21}$

Sin embargo, también son importantes las opciones y alternativas que tienen frente a la situación que viven, es decir, poder saber qué hacer y cómo. En tal sentido, Arensburg y Pujal (2014:1433-1436) destacan la importancia de judicializar la violencia contra las mujeres porque permite sacarla del ámbito privado.

Por otro lado, varias de las mujeres atendidas sí contaban con fuentes de recursos antes de llegar al PAIMEF, pero muchas lo buscaron después del trabajo realizado con las profesionales. La dependencia económica, casi siempre, necesitó romperse para que las mujeres pudieran separarse, o bien transformar en algún sentido las relaciones de género en la familia sin que mediase la separación. La atención en tiendas sencillas de abarrotes dentro de sus propias casas, la elaboración y venta de alimentos también dentro del hogar, la realización de trabajos de costura y tejido, así como de artículos artesanales diversos, el trabajo

\footnotetext{
20 Estudios con perspectiva psicológica y psicoanalítica tendrían que profundizar en la no separación de las usuarias de sus parejas agresoras.

${ }^{21}$ Estas últimas son muy frecuentes entre las mujeres indígenas y seguramente por ello quedaron así asentadas en la Ley de Acceso. En Chiapas se incluyeron a la lista de cinco tipos de violencia de la Ley General tres más, a saber, la violencia moral, la violencia obstétrica y la violencia de los derechos reproductivos. La segunda se refiere al trato deshumanizador del personal de salud, particularmente sufrido por las mujeres indígenas; la tercera abarca la omisión o acción que limite o vulnere el derecho de las mujeres a decidir sobre su función reproductiva (Ley de Acceso, Artículo 6, fracciones VII y VIII).
} 
doméstico remunerado, constituyen las vías más frecuentes para la obtención de ingresos.

Tuvieran o no un trabajo remunerado previamente a la unión con la pareja, el proceso terapéutico les ayuda a tomar la decisión de buscar un medio de vida:

Todo este tiempo lo había pasado como ama de casa. Gracias a Dios ahora pude conseguir un trabajito de un día en el CONAFE, como facilitadora de pláticas para mujeres, en un pueblo aquí por Zinacantán. Y ya llevo como dos sesiones; apenas todavía empecé. Pero he tomado los cursos, las capacitaciones, y la verdad es que me ha hecho mucho bien (San Cristóbal de Las Casas, usuaria).

Finalmente, dado que el modelo de atención en el PAIMEF está planteado para los dos tipos de apoyo, legal y psicológico, las profesionales insisten a las usuarias sobre la necesidad de recibir las terapias, pero no siempre tienen éxito, «Pues en la terapia apenas vine dos veces y he fallado porque no me da tiempo; tengo

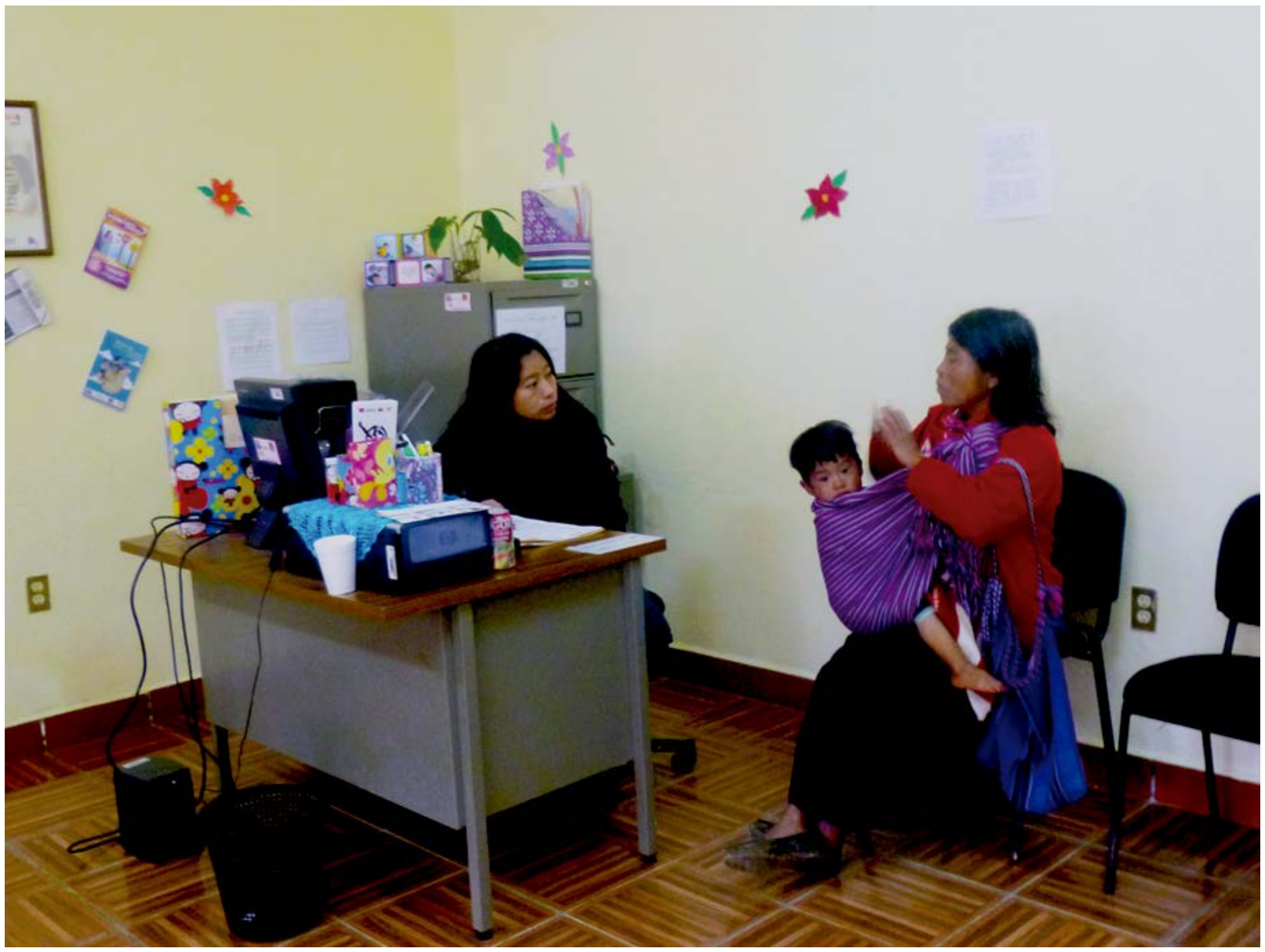


que trabajar, tengo que llevar a mis hijos a la escuela y no he seguido. Y ahora no sé si me va a dar tiempo de seguir viniendo a la terapia» (Tecpatán, usuaria).

El mayor interés en las terapias psicológicas lo encontré entre mujeres de las urbes. Sin embargo, también hay pobladoras urbanas que dejan de asistir a estas terapias, como los casos de dos hondureñas (Tuzantán y Ciudad Hidalgo) para quienes Chiapas era el lugar de paso necesario en su trayecto a Estados Unidos, pero decidieron quedarse en México al encontrar un compañero mexicano. En este caso, y como ya se ha señalado en otros estudios (Alonso y Labrador 2010), su persistente condición de migrantes, como la llamo, pese a tener varios años de vivir con una pareja mexicana, de hecho las hace vulnerables porque en cierto sentido las condena al silencio bajo el riesgo de ser denunciadas por el propio compañero, como lo expresaron. Por alguna razón, el hijo común que una de ellas tenía con el compañero mexicano no facilitaba superar su condición de migrante. No obstante, el hecho de haber atendido el llamado para las entrevistas que les haría en el Programa de Acompañamiento fue un indicador de la buena percepción que tenían del PAIMEF.22

Finalmente, entre los casos conocidos hubo tres que refirieron positivamente la atención a menores de edad: en Chiapa de Corzo, Villaflores y Tapachula. El cambio observado por las madres en sus hijos o hijas se reflejaba en la modificación de las pautas de conducta de estos últimos: un mejor desempeño escolar, dejar de producirse heridas a sí mismos o controlar mejor sus esfínteres. No conocí casos de infantes indígenas, posiblemente porque las terapias psicológicas no son vistas como algo importante en el proceso individual y familiar.

El desinterés por las terapias psicológicas, de hecho, parece más acentuado entre las usuarias de las unidades ubicadas en municipios indígenas; sin embargo, no pude saber si esto se debía al hecho de que el servicio psicológico se hace en un idioma que no es el propio, porque las visitas a la oficina del PAIMEF suponen un gasto más allá de las posibilidades de las usuarias que viven en las comunidades, o bien porque las mujeres no piensan en sí mismas y su propio proceso de sanación, sino ante todo en los aspectos materiales de supervivencia dada su precaria posición.

22 Pese a todo, no siempre se identifica al PAIMEF como un programa independiente y con identidad propia; de hecho algunas veces se le confunde todavía con el DIF (sobre todo allí donde la oficina del PAIMEF se ubica en las instalaciones del DIF). Esta situación me llevó a sugerir que se trabajara este aspecto, considerando que su reconocimiento preciso constituye un capital simbólico importante que permitiría defenderlo y fortalecerlo en condiciones adversas. 


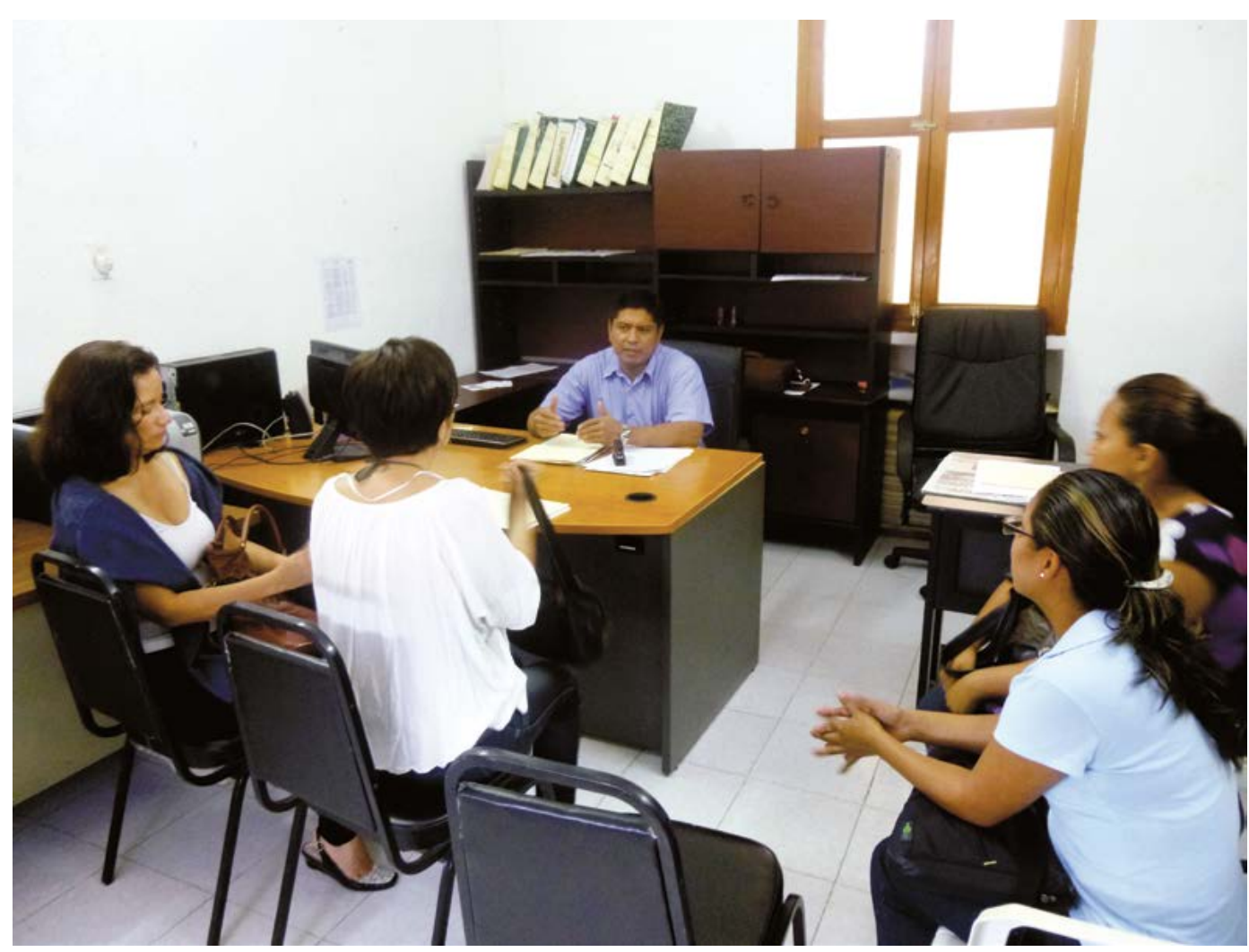

Se puede entender que las usuarias en condiciones de separación de hecho o como posibilidad futura busquen ante todo la protección de sus hijos e hijas mediante el reconocimiento de paternidad y/o las pensiones alimenticias. Sin embargo, este cuadro se liga, sin duda, a la fuerte naturalización de la dominación masculina (Bourdieu 1999) y la naturalización de la violencia, lo que tiene que trabajarse en el idioma indígena respectivo.

\section{CONCLUSIONES}

Pese a todas las limitaciones, el PAIMEF constituye uno de los logros más importantes de los últimos tiempos con relación a la lucha contra la violencia hacia las mujeres en México. La voluntad y el compromiso de quienes están al frente de las unidades - algo que solemos encontrar en las prácticas feministas - juegan un papel decisivo en los buenos resultados que ha tenido: esto he intentado mostrar en las páginas previas, más allá de reconocer que el PAIMEF por sí mismo es, en términos generales, un programa de política pública diseñado y puesto en operación de manera adecuada. 
El camino andado en el conocimiento y la práctica de los derechos entre las usuarias está en cierne, si bien los derechos tienen sentido en todo caso a partir de la concreción de sus demandas económicas. Llegar a identificar una serie de demandas «prácticas», como la pensión alimenticia y el reconocimiento de paternidad, o «estratégicas», como no querer vivir más violencia, son pasos importantes en el proceso de las mujeres en situación de violencia.

Sin embargo, la asunción del derecho a una vida libre de violencia va todavía más allá de lo anterior al replantear de conjunto las relaciones asimétricas y desiguales entre hombres y mujeres. Aprenderlo como tal abriría la puerta para una nueva educación en la familia y la sociedad. Para el derecho a una vida libre de violencia, en particular, el camino se allana y a ello contribuye no solo el trabajo de las organizaciones civiles, sino también, más recientemente, el de las instituciones gubernamentales. Un punto este que podría fortalecerse significativamente no para borrar la tradicional y fuerte frontera entre Estado y sociedad civil, pero sí para conjuntar esfuerzos en un problema que reproduce el sistema de dominación masculina.

Los alcances y las limitaciones del programa en Chiapas no dejan duda sobre su impacto positivo en la vida de las usuarias. Su permanencia, su fortalecimiento y sus necesarias transformaciones sobre la base de los diagnósticos, el replanteamiento del modelo y las investigaciones ya aludidas constituyen, sin embargo, la mejor garantía para elevar la calidad de la atención integral a mujeres que viven violencia. Además de la mejora de las instalaciones de las unidades del PAIMEF, dos elementos centrales destacan por su urgente transformación: la débil vinculación o coordinación institucional, por un lado, y la ausencia de dominio de los idiomas originarios entre las profesionales en municipios con población indígena, por otro.

\section{FUENTES DE CONSULTA}

Álvarez, Ofelia, 2006, «El enfoque de género y la violencia contra las mujeres. Aproximación al análisis de los conceptos», Revista Venezolana de Estudios de la Mujer, 3(1), pp. 45-54.

Alonso, Edurne y Francisco Labrador, 2010, «Eficacia de un Programa de Intervención para el Trastorno de Estrés Postraumático en Mujeres Inmigrantes Víctimas de Violencia de Pareja: Un Estudio Piloto», Interamerican Journal of Psychology, 44(3), pp. 547-559. 
Arce-Rodríguez, Mercedes, 2006, «Género y violencia», Agricultura, Sociedady Desarrollo, 3(1), pp. 77-90.

Arensburg Castelli, Svenska y Margot Pujal Llombart 2014, «Aproximación a las formas de subjetivación jurídica en mujeres víctimas de violencia doméstica», Universitas Psychologica, 13(4), pp. 1429-1440.

Bello-Urrego, Alejandra del Rocío, 2013, «Sexo/género, violencias y derechos humanos: perspectivas conceptuales para el abordaje de la violencia basada en género contra las mujeres desde el sector salud», Revista Colombiana de Psquiatría, 2(1), pp. 108-119.

Bourdieu, Pierre 1999 [1998], La dominación masculina, Barcelona, Anagrama.

Cameras Myers, Mariel S., 2013, Las Siete Alianzas. Género y poder en las prácticas de justicia en Oxchuc, Chiapas, tesis de maestría inédita, México, Centro de Estudios Superiores de México y Centroamérica/Universidad de Ciencias y Artes de Chiapas.

Carlsen, Laura, 1999, "Autonomía indígena y usos y costumbres: la innovación de la tradición», Chiapas, 8, en <http://www.revistachiapas.org/carlsen8.html>

Castro Apreza, Inés, 2004, «San Pedro Chenalhó: la cúspide de las violencias en tiempos de guerra», en Maya Lorena Pérez (coord.), Tejiendo historias. Tierra, género y poder en Chiapas, México, Instituto Nacional de Antropología e Historia, pp. 321-353. 2010, Las Instancias Municipales de las Mujeres en el Estado de Chiapas. Un balance, México, CEDH.

2012a, Programa de acompañamiento y mejora de la SEDEM, de las acciones del proyecto PAIMEF 2012 y los servicios de atención para mujeres en situación de violencia, en su caso, sus hijos e hijas, Meta A.IV.3, México, Sedesol/Indesol/PAIMEF/ Gobierno del Estado de Chiapas.

2012b, Protocolos por Regiones, México, Sedesol/Indesol/PAIMEF/Gobierno del Estado de Chiapas.

2016, «Relaciones de género. Lucha y conquista de los derechos de las mujeres (1970-2010)», en José del Val, Carolina Sánchez y Carlos Zolla (coord.), Estado del desarrollo económico y social de los pueblos indígenas de Chiapas, t. II, México, PUIC-UNAM, SEDESPI, pp. 459-496.

Dorotinsky, Deborah, 1990, «Investigación sobre costumbre legal indígena en los Altos de Chiapas (1940-1970)», en Rodolfo Stavenhagen y Diego Iturralde (comps.), Entre la ley y la costumbre. El derecho consuetudinario indígena en América Latina, México, Instituto Indigenista Iberoamericano/Instituto Interamericano de Derechos Humanos, pp. 65-94.

Espinosa, Gisela, 2009, Cuatro vertientes del feminismo en México, México, Universidad Autónoma Metropolitana-Xochimilco.

Freyermuth Enciso, Graciela, 2004a, Las mujeres de humo. Morir en Chenalhó: género, etnia y generación, factores constitutivos del riesgo durante la maternidad, México, Centro de Investigaciones y Estudios Superiores en Antropología Social/Porrúa.

2004b, «La violencia de género como factor de riesgo en la maternidad», en Marta Torres Falcón (coord.), Violencia contra las mujeres en contextos urbanos y rurales, México, El Colegio de México, pp. 83-110. 
Freyermuth Enciso, Graciela y María Cristina Manca, 2000, Luna golpeada: morir durante la maternidad. Investigaciones, acciones y atención médica en Chapas y otras experiencias en torno a la mortalidad materna, México, Acasac.

Femenías, María Luisa y Paula Soza Ross, 2009, «Poder y violencia sobre el cuerpo de las mujeres», Sociologias, 21, pp. 42-65.

García, Carmen Teresa, Malva Moreno y Carmen Cristina Silva, 2003, «Violencia de género en la región andina venezolana», Otras Miradas, 3(2), pp. 66-82.

Garmendia, Fausto, Alberto Perales, Eva Miranda, Pedro Mendoza, Walter Calderón y Jorge Miano, 2010, «Experiencias para la capacitación de recursos humanos en salud para la atención integral de víctimas de violencia en una zona urbano marginal de Lima, Perú», Revista Peruana de Medicina Experimental y Salud Pública, 27(4), pp. 629-634.

Garza Caligaris, Anna María 2002, Género, Interlegalidad y Conflicto en San Pedro Chenalhó, México, Programa de Investigaciones Multidisciplinarias sobre Mesoamérica y el Sureste/Instituto de Estudios Indígenas.

Garza, Anna María y Sonia Toledo, 2004, «Mujeres, agrarismo y militancia. Chiapas en la década de los ochenta», en Maya Lorena Pérez (coord.), Tejiendo historias. Tierra, género y poder en Chiapas, México, Instituto Nacional de Antropología e Historia, pp. 191-215.

Gimeno Reinoso, Beatriz y Violeta Barrientos Silva, 2009, "Violencia de género versus violencia doméstica: la importancia de la especificidad», Revista Venezolana de Estudios de la Mujer, 14(32), pp. 99-124.

González Montes, Soledad y Rosario Valdez Santiago, 2008, «Violencia hacia las mujeres en ocho regiones indígenas de México: notas metodológicas en torno a la Encuesta Nacional sobre Salud y Derechos de las Mujeres Indígenas (Ensadem)», Estudios Sociológicos, 226, pp. 435-450.

Hernández del Castillo, Rosalba Aída, 2002, «¿Guerra fraticida o estrategia etnocida? Las mujeres frente a la violencia política en Chiapas», en Jacorzynski, Witold (coord.), Estudios sobre la Violencia. Teoría y práctica, México, CIESAS/Porrúa, pp. 92-122.

2004, «El derecho positivo y la costumbre jurídica: las mujeres indígenas de Chiapas y sus luchas por el acceso a la justicia», en Marta Torres Falcón (coord.), Violencia contra las mujeres en contextos urbanos y rurales, México, El Colegio de México, pp. 110-159.

Hernández del Castillo, Rosalba Aída (coord.), 1998, La otra palabra, mujeres y violencia en Chiapas. Antes y después de Acteal, México, CIESAS.

Incháustegui Romero, Teresa y Edith Olivares Ferreto, 2011, Modelo ecológico para una vida libre de violencia de género en ciudades seguras, México, Comisión Nacional para Prevenir y Erradicar la Violencia contra las Mujeres.

Jiménez Domínguez, Tatiana, 2011, La violencia doméstica en Chiapas. Discursos periodísticos y legales en época de cambios 1930-1940, Chiapas, México, Consejo Estatal de la Cultura y las Artes (series Umbrales 32).

López Angulo, Laura Magda, 2009, «Guía metodológica para la asistencia a mujeres víctimas de violencia», MediSur, 7(5), pp. 62-83. 
López, Rosa, 2006, «Las mujeres en Chiapas: contra la violencia y por igualdad de derechos», en Raquel Gutiérrez y Fabiola Escárzaga (coord.), Movimiento indígena en América Latina: resistencia y proyecto alternativo, México, Juan Pablos, pp 346-348.

Moreno, Sandra P., Martha R. Barreto, Pablo A. Sanabria, Luis A. González y Adriana Pinzón, 2013, «Evaluación de la atención a víctimas de la violencia sexual: experiencia en tres hospital de Bogotá», Revista Facultad Nacional de Salud Pública, 31(2), pp 195-200.

Olivera Bustamante, Mercedes, 1979, «Sobre la explotación y opresión de las mujeres acasilladas en Chiapas», en Cuadernos Agrarios, 4(9), pp. 43-55.

Olivera Bustamante, Mercedes (coord.), 2008, Violencia feminicida en Chiapas. Razones visibles y ocultas de nuestras luchas, resistencias y rebeldías, México, UNICACH.

Osborne, Raquel, 2008, "De la "violencia" (de género) a las 'cifras de la violencia': Una cuestión política», EMPIRIA. Revista de Metodología en Ciencias Sociales, 15, pp. 99-124.

Rivera-Garretas, María Milagros, 2001, «La violencia contra las mujeres no es violencia de género», DUODA. Revista d'Estudis Feministes, 21, pp. 37-42.

Rodríguez Castillo, Luis, 2009, «Diagnóstico a Instancias Municipales responsables de la instrumentación de las políticas de igualdad entre mujeres y hombres. Región Sureste», en Instancias Municipales de la Mujer en México, México, Comisión Nacional de Derechos Humanos.

Romero Mendoza, Vanessa María y José Amar Amar, 2009, «Modelo de atención integral a Mujeres, niñas y niños víctimas de violencia intrafamiliar llevado a cabo en centro de atención de la ciudad de Barranquilla (Colombia)», Investigación \& Desarrollo, 17(1), pp. 26-61.

Rus, Jan, 2000, «Un juzgado, dos culturas: estrategia retórica e interferencia cultural en una comunidad maya en transformación», en Anuario de Estudios Indígenas VIII, México, Instituto de Estudios Indígenas/Universidad Autónoma de Chiapas.

Salazar Flores, Nashyelli, 2013, «Feminismos, poderes y mujeres. El feminismo civil en San Cristóbal, del poder individual al poder social», tesis de maestría inédita, CESMECA-UNICACH, Chiapas, México.

Sampedro Arrubla, Julio Andrés, Vanessa Suelt Cock, Consuelo Quiñones Camargo y Javier D. Coronado Díaz, 2014, «Proyecto de atención a víctimas de violencia sexual en el consultorio jurídico de la Pontificia Universidad Javeriana», Vniversitas, 129, pp. 275-315.

Scott, Joan W., 2000[1986], «El género: una categoría útil para el análisis histórico», El género, en Marta Lamas (comp.), La construcción cultural de la diferencia sexual, compilado por el Programa Universitario de Género, Universidad Nacional Autónoma de México, pp. 265-302.

Soriano Hernández, Silvia, 2005, «Mujeres en Chiapas y Guatemala: sin frontera para la violencia», en Diana Guillén (coord.), Chiapas: frontera en movimiento, México, Instituto Mora, pp. 153-212.

Taus, Patricia A., 2014, «La igualdad de género y el acceso a la justicia de las mujeres víctimas de violencia en la región dentro del sistema interamericano de protección de 
los derechos humanos», IUS. Revista del Instituto de Ciencias Jurídicas de Puebla, A.C., VIII(34), pp. 21-41.

Tiburcio Sainz, Marcela, Guillermina Natera Rey y Shoshana Berenzon Gorn, 2010, «Utilización de servicios de atención a la salud mental en mujeres víctimas de violencia conyugal», Salud Mental, 33(3), pp. 243-248.

Toledo Tello, Sonia y Anna María Garza Caligaris, 2003, «Las mujeres y el movimiento agrario en Chiapas imágenes y estereotipos», Anuario de Estudios Indígenas, 9, pp. 247-268.

Tuñón Pablos, Esperanza (coord.), 1997, Género y salud en el sureste de México, México, Ecosur-Universidad Juárez Autónoma de Tabasco.

Valdivia Dounce, Teresa, 1994, Costumbre jurídica indígena (bibliografía comentada), México, Instituto Nacional Indigenista.

\section{Documentos}

Cámara de Diputados del H. Congreso de la Unión, 2007, Ley general de acceso de las mujeres a una vida libre de violencia, <file:///D:/Archivos\%20Fausto/Desktop/violencia.pdf> [consulta: 15 de marzo de 2016].

Gobierno del Estado de Chiapas, 2010, Ley Orgánica Municipal del Estado de Chiapas, Secretaría de Hacienda y Poder Ejecutivo del Estado de Chiapas, México, <http:// www.ordenjuridico.gob.mx/Documentos/Estatal/Chiapas/Todos\%20los\%20 Municipios/wo45262.pdf> [consulta: 15 de marzo de 2016]

Gobierno de México, 2015, Programa de Apoyo a las instancias de Mujeres, Indesol, México, <http://www.indesol.gob.mx/es/web_indesol/Programa_de_Apoyo_a_las_ Instancias_de_Mujeres> [consulta: 15 de marzo de 2016]

Poder Judicial del estado de Chiapas, 2007, «Ley de Acceso a una Vida Libre de Violencia para las Mujeres en el Estado de Chiapas», Diario Oficial, <http://www.poderjudicialchiapas.gob.mx/Pagina/legislacion.php> [consulta: 15 de marzo de 2016]

Poder Judicial del estado de Chiapas, 2009, "Ley para la Igualdad entre Hombres y Mujeres para el Estado de Chiapas», Diario Oficial, <http://www.poderjudicialchiapas.gob.mx/Pagina/legislacion.php> [consulta: 15 de marzo de 2016] consulta: 15 de marzo de 2016].

Secretaría de Salud, 2009, Modelo Integrado para la Prevención y Atención de la Violencia Familiar y Sexual. Manuel Operativo, Centro Nacional de Equidad de Género y Salud Reproductiva en colaboración con Mujer y Medio Ambiente A. C. y con IPAS México, A. C. y con el apoyo del Programa para el Desarrollo de las Naciones Unidas, PNUD. México. <http://www.gobernacion.gob.mx/work/models/SEGOB/Resource/689/1/ images/MODELOE.PDF> [consulta: 15 de marzo de 2016]

SEDEM-Chiapas, 2012, Modelo de Atención Integral a las Mujeres Víctimas de Violencia de Género, Gobierno del Estado de Chiapas, <http://www.sedem.chiapas.gob.mx/ docs/leyes/Ley.pdf> [consulta: 15 de marzo de 2016].

Sedesol, Indesol y PAIMEF, 2010, Diagnóstico de los Centros, Unidades y Ventanilla Única de Atención a mujeres, sus hijas e hijos en situación de violencia para detectar for- 
talezas y debilidades, así como las oportunidades de mejora en la calidad de los servicios y el Modelo Integral de Atención, <http://cedoc.inmujeres.gob.mx/PAIMEF/ CHIS_PAIMEF_dx_centros-unidades_2010.pdf> [consulta: 15 de marzo de 2016].

Sedesol, Indesol, PAIMEF y Gobierno del Estado de Chiapas, 2011, Modelo de Atención a Mujeres en Situación de Violencia. Apegado a lo establecido en la Ley de Acceso a una Vida Libre de Violencia para las Mujeres en el Estado de Chiapas, SEDEM, Inesol, México, <http://vidasinviolencia.inmujeres.gob.mx/sites/default/files/MODELO\%20 DE\%20ATENCION\%20PAIMEF(CHIAPAS).pdf> [consulta: 15 de marzo de 2016].

Ulloa Ziáurriz, María Teresa, Margarita Garrido Martínez y María Elene Farrera, 2009, Resultados de la situación de la violencia social y de género en el Estado de Chiapas, México, Observatorio de Violencia Social y de Género en el Estado de Chiapas/ Instituto Nacional de Desarrollo Social/Defensoras Populares-UNACH.

Fecha de recepción: 24 de noviembre de 2015

Fecha de aceptación: 26 de marzo de 2016 